\title{
SECOND LANGUAGE INSTRUCTION DOES MAKE A DIFFERENCE
}

\author{
Evidence from an Empirical Study \\ of SL Relativization
}

\section{Catherine Doughty}

University of Sydney

\begin{abstract}
A number of studies on second language $(\mathrm{SL}$ ) instruction point to the hypothesis that instruction is effective, but determining the effect experimentally has been problematic. Overall, three difficulties with previous attempts to demonstrate a causal relationship between $S L$ instruction and second language acquisition can be identified: (a) inappropriate or inadequate research design, (b) failure to operationalize or even to describe the instructional treatment, and (c) choice of SL assessment measures. This article presents the findings of a recent empirical study which (a) show that SL instruction is effective; (b) show that attention to form, either via detailed analysis of structure or highlighting of target language (TL) structures in context, promotes acquisition of interlanguage (IL) grammar, but that only the latter comes hand-in-hand with comprehension of input; and (c) replicate earlier findings suggesting an important role for markedness theory in instructed IL development.
\end{abstract}

There have been several approaches to the evaluation of the effectiveness of second language instruction. Because child language acquisition was universally noted to be incidental, rapid, and successful, and because researchers frequently observed similarities between first and second language acquisition, the early considerations

\footnotetext{
This is an extended version of a paper delivered at the Second Language Research Forum (Los Angeles, UCLA, February 1989). The investigation conducted was my doctoral research (1987-1988). I am deeply grateful to Teresa Pica for her insightful guidance throughout the research project. I also thank Michael Long, Jessica Williams, and the anonymous SSLA reviewers for comments on this article.
} 
of the effect of instruction concentrated on the empirical investigation of second language acquisition (SLA) in comparison with research findings on first language acquisition (FLA) (see Dulay \& Burt, 1974; Hatch, 1983; Krashen, 1982, for reviews). This research direction gradually expanded to include comparisons of SLA in different settings, primarily the instructed versus uninstructed contexts of acquisition, where SLA in the uninstructed context was seen to be "naturalistic" or most like FLA (see Krashen, 1982; Pica, 1983, for reviews). A third approach, one entirely within the context of instructed interlanguage development, ${ }^{1}$ sought to compare the relative effectiveness of different instructional methodologies with respect to the overall proficiency of SL learners (see Long, 1983, 1988a, 1988b; Richards \& Rodgers, 1986, for discussion of methods comparisons). None of these approaches has been sufficient to demonstrate a direct effect of instruction on SLA.

Methodological difficulties may have resulted from the early tendency to compare naturalistic to classroom acquirers. In essence, too many variables intervene in this type of research design, thus resulting in conflicting findings across past studies. For example, there has been wide variation reported in amounts of total (i.e., instructed plus natural) exposure to the TL across groups of instructed and uninstructed subjects (see Long, 1983, for review), and this variable alone could have been responsible for the inconsistency often noted in comparing effect-of-instruction studies.

A second problem has been the repeated failure to consider carefully the nature of the SL instruction provided to subjects. There are really several related problems associated with this failure to operationalize the instructional component of effectof-instruction studies. In past investigations, where the nature of the instruction was mentioned at all, existing "methods" of instruction were merely cited, and never described. In other words, the instruction studied was not operationalized anywhere in the research design beyond receiving a methods label such as "grammar translation," "audiolingualism," or "natural approach." Thus, the actual implementation of the instructional materials was never documented. Most commonly in early studies of instructed versus uninstructed acquirers, instruction was defined merely as a period of time spent attending SL classes and not examined directly at all. Perhaps more important, the instructional components of previous research were not based on any theory of or empirical findings on SLA. Recently, however, SLA research has moved in the direction of investigating learner attention to linguistic code (Long, 1988b; Schmidt \& Frota, 1986), and it is within this framework of code-focused instruction that the present study was conducted.

Finally, in effect-of-instruction experimentation, as in all areas of SLA investigation, the assessment of IL development has proven to be difficult. Generally, the approach to SL assessment has been that of overall proficiency compared at times before and after the period of instruction. This approach is not inherently problematic, but it has tended to compound the cloudiness surrounding the lack of instructional operationalization. In other words, studies have attempted to connect the "black box" instructional variable to the little-understood process of SLA by using global proficiency measures. It is, therefore, not surprising that research results have not been robustly supportive of SL instruction. 


\section{EVIDENCE FOR THE EFFECTIVENESS OF SECOND LANGUAGE INSTRUCTION}

\section{Second Versus First Language Acquisition}

As noted, the early approach to investigating SLA derived from a comparison of FLA and SLA under so-called natural conditions. This is because-owing both to the universal success of FLA and to the relatively poor outcome of instructed SLAnaturalistic SLA (i.e., the type of SLA most like FLA) was thought to be a more appropriate focus of investigation than was instructed IL development. The morpheme studies, which hypothesized a common developmental order for the acquisition of a set of English morphemes by FL and SL learners, were conducted within this empirical framework (see, e.g., Bailey, Madden, \& Krashen, 1974; Dulay \& Burt, 1973). The similarity of the morpheme accuracy rank orders for FLA and SLA led a number of researchers at the time to postulate a natural order of language acquisition, and the general conclusion drawn from the morpheme studies was that learners of different backgrounds, different ages, and different kinds and amounts of instruction or exposure to English acquire morphemes in essentially the same order (Lightbown, 1981, 1983, in referring to the morpheme studies). Thus, at this early stage in SLA research, the role of instruction was characterized as minimal at best and detrimental at worst (Krashen, 1977).

\section{Instructed Versus Uninstructed Second Language Acquisition}

Subsequently, morpheme studies attempted to determine whether instructed SL learning involves processes similar to or different from those inherent in naturalistic SLA by comparing the SL production of instructed learners and naturalistic acquirers. Conflicting results obtained once again. In some studies, no difference was found between instructed and uninstructed groups of subjects (e.g., Perkins \& Larsen-Freeman, 1978), but in other investigations, different morpheme orders were observed for naturalistic versus instructed language acquirers (e.g., Sajavarra, 1981). Problems of experimental design are generally cited as responsible for the lack of comparability among morpheme studies (Pica, 1983). Notably, virtually all the socalled naturalistic acquirers had had at least some amount of instruction prior to their participation in the investigations, and perhaps even this limited amount of instruction affected their IL development, thus obscuring findings relevant to the question of untutored language acquisition processes. Furthermore, the choice of rank order of unrelated morphemes as the criterion of comparison in these investigations necessarily restricted researchers to conclusions about the relative ordering of the morphemes studied and left unanswered questions about the effects of acquisitional context on the process of acquiring the morphemes. The lack of consistency across findings of morphemes studies, together with emerging findings regarding differences between child and adult language acquisition (Hatch, 1983; Krashen, Scarcella, \& Long, 1982), led researchers to focus on other aspects of the TL production of instructed versus naturalistic SL acquirers. 
Rather than investigating particular TL features (like morphemes), these production studies compared the global SL ability of subjects enrolled in, or just graduated from, SL programs to that of subjects who had never received any instruction. For the most part, findings of comparisons of naturalistic acquirers and instructed SL learners failed to show any advantages for SL instruction, and, at the time, there were a number of conclusions drawn against any potential benefits for language instruction (Felix, 1981; Krashen, 1977; Wode, 1981). Unfortunately, these conclusions were based on inferences drawn from studies that, rather than attempting to examine the direct effect of instruction on SLA, instead merely noted similarities between the IL production of instructed and uninstructed subjects.

Partly in reaction to the prohibitions regarding the efficacy of instruction, Long (1983) posed the (well-known by now) question, "Does second language instruction make a difference?" To answer this question, Long (1983) took into account a number of previously undetected experimental design flaws and conducted a metaanalysis of the effect-of-instruction studies in order to refute the premature suggestion that there is "no difference between programs of exposure only and the same total amount of instruction plus exposure for children, adolescents, and adults" (p. 362). The overall conclusion drawn by Long was that, based on the sum total of the evidence and in consideration of the numerous methodological flaws in the early studies whose findings seemed counter to the overall trend, the benefit of SL instruction was evident for child and adult SLA, at various levels of proficiency and in a variety of language acquisition contexts.

In an updated review of the instructed IL development research, Long (1988b) likewise concluded that instruction is beneficial to learners, particularly in the areas of SLA processes, rate of SLA, and level of ultimate attainment. However, Long (1988b) cautioned that "there has been insufficient research to warrant firm conclusions in any area we have examined" and consequently stressed that "future research on this issue must be conducted with greater rigor than has typically been the case to date" (pp. 135-136). In particular, Long called for greater care in subject selection, in following procedures of employing experimental and control groups to which subjects are randomly assigned, and in "select[ing] for teaching experiments those aspects of the SL that are 'learnable' at the time the instruction is provided" (p. 136).

\section{The Comparative Effectiveness of Methods on Second Language Acquisition}

The remaining approach to examining the effect of instruction on SLA has been to compare the influence of various methods on IL development. Such global methods comparisons have proven to be extremely difficult to accomplish, and none has ever shown the superiority of one method of instruction over another. The difficulty in obtaining conclusive results based on a comparison of methods has led many methods evaluators to conclude that methodology may not be the critical variable in successful language learning (Kennedy, 1973). However, the primary difficulty with methods comparisons may have been a lack of detailed description of each 
method as it is implemented in the classroom by individual teachers (Richards \& Rodgers, 1986).

In sum, the existing body of research on the effects of instruction on SLA suggests-but does not yet robustly provide support-that instruction positively affects acquisition. Several important insights, gained through examining previous attempts to document the effect of SL instruction on SLA, shaped the approach of the study to be reported here. The present study was motivated by the urgent need for rigorous and empirical research investigating the effect of instruction on IL development, taking into account considerations of (a) research design such as experimental control and differentiation of exposure and instruction, (b) operationalization of instructional procedures and principled materials development based on SLA theory, and (c) appropriate measurement of SLA. It thus differs from previous studies in the research methods adopted, in the way in which the variable of instruction was examined, in the way in which instructional materials were developed and presented to learners, and in the way in which change in the SL ability of the subjects was assessed. The general research questions addressed in this study were:

1. Does SL instruction make a difference?

2. If so, do different types of (carefully operationalized) instructional procedures differently affect SLA? and

3. How can SLA theory and previous findings be incorporated into SL instruction?

\section{METHOD}

\section{The Target of Instruction: Relativization}

One grammatical subsystem of English was selected as the target of instruction in order to alleviate earlier problems of lack of instructional operationalization and difficulties in SLA assessment. Because considerable descriptive and some acquisitional research could provide the basis for well-informed experimental and instructional design decisions, relativization was the subsystem of English that was chosen. The study was limited to restrictive relative clauses since all the research that informed the instructional treatment designs has emphasized restrictive relativization. A restrictive relative clause is one that provides the information necessary to clarify the referent of the head noun (HN), as shown in (1a) $(\mathrm{RP}=$ relative pronoun). Conversely, a nonrestrictive relative clause provides new information about a head noun whose referent is assumed to be known to the interlocutor, as in (1b).

(1a) A woman \{who is a professional architect\} suggested the playground design.

HN RP

(1b) Your neighbor on the left, $\{w h o$ is a professional architect $\}$, suggested the playground design. HN $\mathrm{RP}$

\section{The Sequence of Instruction}

Of particular concern to SLA researchers and of potential utility in instructional design is the hypothesized existence of natural sequences of development within 
The people who live in Philadelphia are busy.

SS

I know some people who live in Philadelphia.

The people who we know live in Phildelphia.

OS

I know the people who you know.

$S(D) O$

The people who I gave the tickets to live in Philadelphia.

O(D)O

You saw the people who I gave the tickets to.

The people who you talked with live in Philadelphia.

$S(I) O$

I know the people who you talked with.

The people whose name is Taylor live in Philadelphia.

I know the people whose name is Taylor.

O(I)O

SO(PREP)

OO(PREP)

?The only person who I am taller than lives in Philadelphia.

?! know the only person who you are taller than.

S-

0 -

SO(COMP)

OO(COMP)

$\begin{array}{ll}S=\text { Subject } & I=\text { Indirect } \\ O=\text { Object } & \text { PREP }=\text { Preposition } \\ D=\text { Direct } & \text { COMP = Comparison }\end{array}$

Figure 1. English relative clause types.

grammatical subsystems of the L2. Generally, natural sequences are thought to be indicative of a universal ordering of difficulty, although exactly what constitutes difficulty has not yet been clearly established. The discovery of universal orderings is of crucial importance to the enhancement of instructed IL development because such knowledge bears heavily on decisions regarding the sequencing and timing of instruction. That is, as Pienemann (1985) proposed in the Teachability Hypothesis, any empirical findings about natural developmental sequences must be respected in the design of instructional materials.

Three hypotheses that predict an order of difficulty for relative clause acquisition may be derived from the FLA and SLA relativization literature: the Parallel Function Hypothesis (PFH), the Perceptual Difficulty Hypothesis (PDH), and the Accessibility Hierarchy Hypothesis (AHH). ${ }^{2}$ The PFH and PDH both classify the grammatical functions of the HN and the RP with respect to their function in the matrix and embedded clauses. In complex sentences, the coreferential HN and RP can function either as the subject or the object of their respective clauses. The PFH examines the relationship between the functions of the $\mathrm{HN}$ and the RP in their respective clauses, while the PDH focuses on the location of the relative clause in the matrix sentencethat is, whether the relative clause is left-, center-, or right-embedded. In contrast, the AHH examines only the relative clause itself, with no attention given to the matrix sentence. Typological comparisons have shown that there are six different relative clause types, each representing a specific function of the RP in the relative clause: the subject, the direct object, the indirect object, the object of a preposition, the possessive, or the object of a comparison (Keenan \& Comrie, 1977, 1979).

Figure 1 provides examples of all types of relative clause sentences, categorized according to the analytic systems of each predictor hypothesis. Different difficulty 
orders for English relativization are derived from each of the three predictor hypotheses (see Figure 2). In order to determine the best sequence of presentation of instructional materials for the present study of $\mathrm{L} 2$ relativization, each predictor hypothesis and its logical difficulty order was considered in light of available empirical evidence from FLA and SLA studies. While it is beyond the scope of this article to review the evidence in detail, the findings of relativization studies will now be summarized in terms of the sequence of instruction decision that is germane to the present study.

The PFH was formulated originally to account for first-language relativization and proposes a cognitive-processing interpretation of the syntactic relationship between the function of the $\mathrm{HN}$ in the matrix sentence and the function of the coreferential RP in the embedded relative clause. The PFH assumes that the grammatical functions of the coreferential noun phrases play a significant role in ease of comprehension and, thus, specifically predicts "a strategy of interpreting the grammatical function of the relative pronoun as being the same as its antecedent" (Sheldon, 1974, p. 274). That is, the difficulty order predicted by the PFH is Subject-Subject (SS) and Object-Object (OO) sentences before Subject-Object (SO) and Object-Subject (OS) sentences (see examples in Figures 1 and 2). Though a study by Sheldon (1974) of the order of difficulty in the comprehension of relative clauses by children learning English as their FL indicated that children could better understand sentences in which the head noun and the relative pronoun served the same function in their respective clauses (e.g., SS and $\mathrm{OO}$ relativization), these findings have not been replicable by other FL researchers (Bowerman, 1979), have been directly countered by evidence from studies of comprehension of relative clauses by adult native speakers (Prideaux \& Baker, 1986), and, furthermore, were not supported by an early study of L2 relativization (Gass \& Ard, 1980). Thus, parallel function of head and relativized nouns seems not to be a factor that consistently determines difficulty in processing relative clauses.

A second approach to the prediction of a natural order of difficulty of relative clauses, the $\mathrm{PDH}$, has been derived by taking universal constraints on the process of embedding across languages as a basis for prediction. Kuno (1974) proposed that, due to the limitations of human short-term memory, center-embedding-or the case in which the relative clause interrupts the processing of the matrix sentence-is perceptually the most difficult kind of embedding, as compared with relativization involving right- and left-embedding. Thus, the $\mathrm{PDH}$ predicts a difficulty order of OS and $\mathrm{OO}$ sentences before SS and SO sentences (see examples in Figures 1 and 2). Mixed findings characterize empirical studies that have sought to sustain the PDH. Several studies examining various relativization abilities, such as imitation by both native and nonnative speakers (Cook, 1973), grammaticality judgments by SL learners (Ioup \& Kruse, 1977), adult native-speaker comprehension (Prideaux \& Baker, 1986), and frequency of occurrence of relative clauses in L2 target language production (Schumann, 1980; Stauble, 1978) have shown that sentences with relativization involving center-embedding are more difficult than are sentences in which the relative clause appears either before or after the matrix clause. However, loup (1983) was not able to replicate her earlier findings, and Cook's (1973) findings were split 

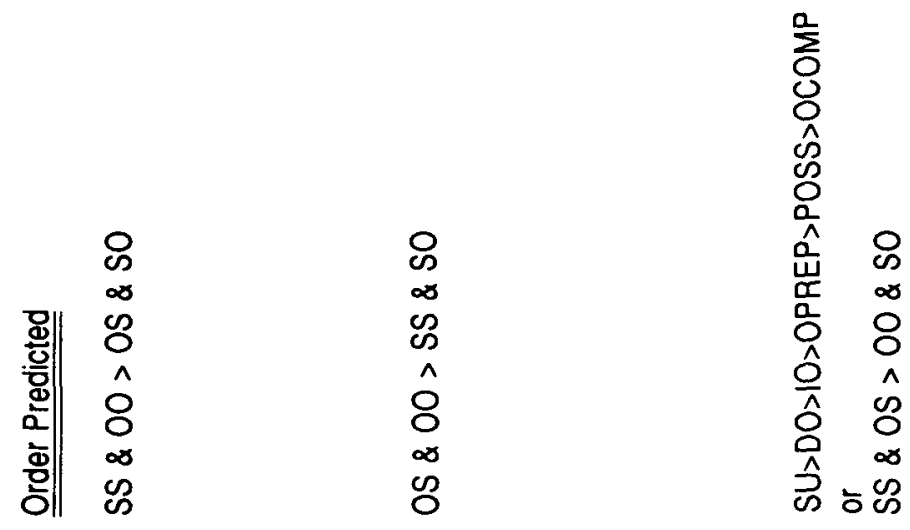

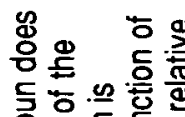

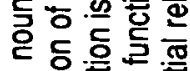

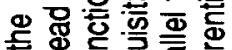

๘.

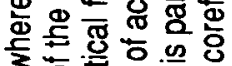

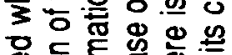

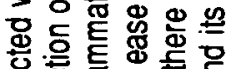

음 는 턴듀

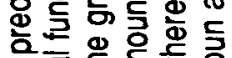

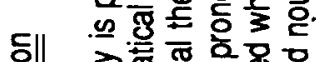

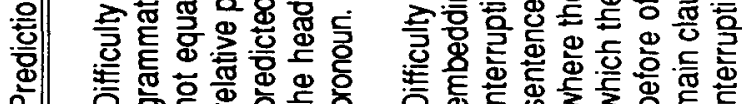

离

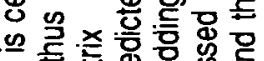

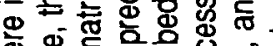
ฆ

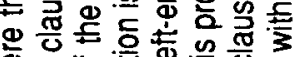

홍

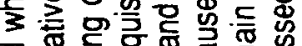

웡

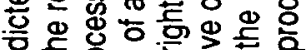

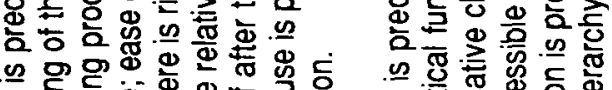

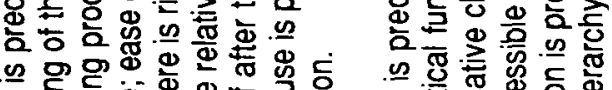

동 능 옹

응응 刃용

\$ $\mathbb{8}$

突

$\Phi$ 这

完宗

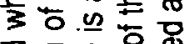

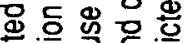

응

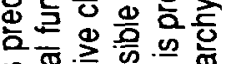

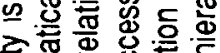

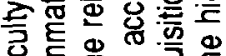

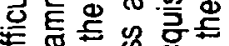

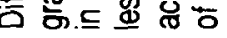

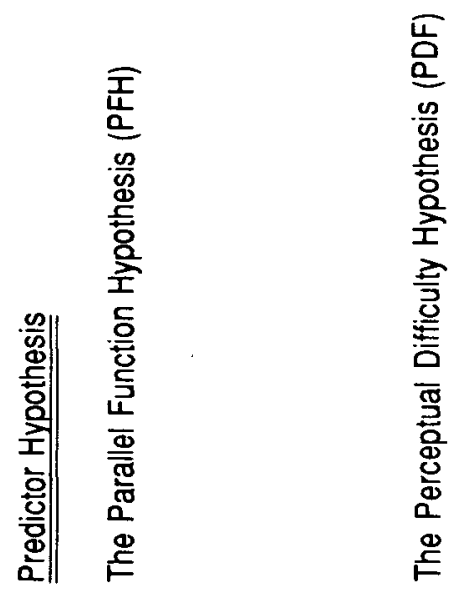

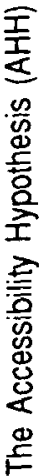


between reliance on a parallel function strategy and constraint by perceptual difficulty. There have been no acquisitional studies conducted that have emanated from the PDH. Thus, while intuitively appealing, the PDH has also not found consistent empirical support.

The third and final hypothesis that can be applied to the prediction of an order of difficulty for relativization, the $\mathrm{AHH}$, is based on a typological markedness. Specifically, although the relativization process differs across languages with regard to the total number of syntactic functions for the relative pronoun in its relative clause, a particular hierarchical ordering of the ease of accessibility of these functions can be described, known as the Noun Phrase Accessibility Hierarchy (NPAH) (Keenan \& Comrie, 1977). Generally, the NPAH proposes that relative clauses in which the relative pronoun functions as the SUBJECT of the clause are universally the easiest or "most accessible." When the RP functions as the object of the clause or indicates a possessive relationship, the implicational accessibility ordering continues as follows: DIRECT OBJECT, then INDIRECT OBJECT, then OBJECT OF A PREPOSITION, then POSSESSIVE, and finally OBJECT OF A COMPARISON (see examples in Figure 1). In terms of the functions of both HN and RP, the difficulty order predicted is SS and OS sentences before OO and $\mathrm{SO}$ sentences (see Figure 2; as noted, the AHH relies only on the function of the $\mathrm{RP}$; this ordering is given for purposes of comparing predictions made by the three hypotheses).

Considerable support for the $\mathrm{AHH}$ as a reasonable predictor of difficulty in relative clause acquisition is evident in both FL and SL production studies. Gass (1979) found that in SL production data, frequency and accuracy of production of relative clauses follows the overall pattern predicted by the NPAH. Hyltenstam's (1984) findings suggested that RP copies (ungrammatical in English, but possible in other languages) were deleted by L2 speakers of Swedish from NP positions generally in the order predicted by the NPAH, regardless of FL background. The findings of FLA studies can also be shown to be predicted by the AHH. Romaine's (1984) study of the FL development of English-speaking children is a case in point. The relative clause data of children (ages 6, 8, and 10 years) learning English as their FL shows that, as the ages of the groups of children increase, the preference for the SUBJECT type of relative clause increases and the use of the OBJECT type of relativization decreases. Romaine reported that the interaction between age and type of relativization was significant in her investigation; thus, while parallel function may explain a very early relative clause processing strategy for children, subsequent relativization acquisition appears to proceed according to the order predicted by the NPAH. In fact, none of the L1 and L2 accuracy or production data violates the ordering predicted by the NPAH (Doughty, 1988).

Findings of three SL acquisitional studies that specifically examined $\mathrm{L} 2$ relativization in the context of the NPAH have also lent preliminary support to the AHH. In a pilot study, Gass (1981) found that subjects who received instruction pertaining to OBJECT OF A PREPOSITION type relative clauses outperformed subjects who received instruction on SUBJECT relative clauses, as measured by percent improvement on post- over pretests of grammaticality judgment in most relative clauses categories. The only exception was that subjects expressly instructed in the SUBJECT type of 
relative clause evidenced $40 \%$ improvement in judging grammaticality of SUBJECT type relative clauses, as compared with $30 \%$ improvement on the part of subjects who had received only OBJECT OF A PREPOSITION type instruction. A study by Eckman, Bell, and Nelson (1988) essentially replicated Gass's (1981) findings. ${ }^{3}$ Pavesi (1986) has shown a possible general effect for instruction on the level of ultimate attainment of relative clauses when attainment (e.g., accurate production of targetlike pronouncopyless relative clauses) is examined within the NPAH framework. She defined the SL experience of two groups of subjects as either formal (having received any SL instruction) or informal (entirely untutored) and found that subjects who had encountered formal contexts for relativization through participating in the planned discourse characteristic of SL classroom instruction proceeded further down the AHH than did subjects who had only been exposed to the informal contexts for relativization characteristic of naturalistic SLA.

The results of the two studies above can be explained in terms of the theory of markedness, as realized in this instance by the markedness conditions that obtain in the typologically related (implicational) positions on the NPAH. An example of how SL development potentially profits from markedness relationships is illustrated in the projection problem, in which there is a seeming paradox resulting from a mismatch between the nature of the input data and the rapid rate and level of ultimate attainment of language acquisition. In describing the projection problem, Zobl (1985) posited that:

markedness conditions represent the abstract structuring principles of the input. ... The marked conditions of concern ... are categories that enter into implicational relations ... and oppositions which, in certain contexts, are neutralized in favor of one of the contrasting terms. It is worth noting that the marked versus unmarked values defined by these procedures have in common an opposition between, respectively, what is more restricted and specific ... and what is distributionally more frequent and general. The markedness conditions characterizing a set of input data make possible two kinds of acquisition of linguistic knowledge which allow the grammar to overcome the data limitations:

(1) acquisition via markedness implications and (2) acquisition via correlations between markedness of different but related parameters. Both acquisition procedures are projection procedures in that they permit the learner to arrive at a knowledge of properties of the target language that are not represented in a set of input data. (p. 330)

If the projection model is correct, there are obvious implications for the sequencing of materials in their presentation to learners. The most efficient sequencing would not be devised from "simplest" to "most difficult," but rather would be one that allows the learner to profit from markedness conditions in order to project the particulars of a grammatical subsystem from one linguistic context (for which there are available data) to another (for which there are no data). Zobl's findings in studies of the acquisition of English possessive determiners have generally supported the projection model $(1983,1985)$. In view of the above findings in support of the AHH 
and the potential advantages to learners inherent in markedness relations, OBJECT OF A PREPOSITION relative clauses were selected as the focus of the instructional treatment presented to subjects in the present relativization experiment. ${ }^{4}$

\section{Subjects}

The subjects were 20 international students (10 male, 10 female), all studying English as a second language (ESL) at the middle proficiency levels of an intensive English institute in Philadelphia. The primary criterion in selecting subjects was that they have little knowledge of English relativization. To be sure that subjects could potentially benefit from instruction in relativization, a preliminary, institutewide test of grammaticality judgments on 48 sentences with relative clauses was conducted one semester prior to the experiment. This pilot test was intended to identify the level at which relativization ability begins to appear. As such, the measure was administered in all classes and at all levels of the intensive English institute, and revealed that of the six levels at the institute, students in the lowest level $(100 / 200)$ could not understand the grammaticality judgment task, and the majority of students at the two highest levels ( 600 and 700 ) had already acquired considerable knowledge of relativization. Therefore, it was determined that very beginning and most advanced students would not be allowed to participate as subjects in the study.

Subjects for the experiment were recruited from the same population to which the level identification test was given. Two 400-level classes were visited personally by the researcher, who explained the requirements of participation. The 16 subjects from the two 400-level classes all participated in the study. In addition, one 300-level and three 500-level students heard about the experiment and volunteered to participate. Several students from the two highest levels also inquired, but they were told that the instruction focused on an aspect of English that they already knew and that, therefore, they would not be likely to benefit from the instruction.

Subjects were native speakers of French (1), Italian (2), Japanese (10), Mandarin (2), Russian (1), Spanish (2), and Turkish (2). The relativization facts of all subjects' L1s are similar to those of English. The one exception is that while OBJECT OF A COMPARISON relativization is questionable in English, it is disallowed in all the first languages of the subjects.

Length of stay (LOS) in the United States was generally short for all subjects, ranging from 1 to 15 months $(\bar{X}$ LOS $=3.7$ months). All subjects reported English as a foreign language (EFL) instruction at the high school and university levels prior to coming to the United States $(\bar{X}$ TOEFL $=424)$, and all had attended either junior college, college, or university in their home countries. Thus, subjects were of a generally high level of education. The majority of the subjects attended exactly the same ESL classes (i.e., the 400 -level classes), and all subjects reported very little out-of-class contact with native speakers, complaining of roommates with the same L1 and not enough opportunity to "meet Americans."

\section{Procedure}

This investigation followed an experimental design that included a control group and the use of a pretest and a posttest. Subjects were randomly assigned to one of 
three groups: two experimental groups and one control group. Improvement from pretest to posttest in relativization ability was compared among subjects who were exposed to relative clauses but received no instruction in relativization (the controls) and subjects who, in addition to exposure, were provided with an instructional treatment aimed at improving their ability to relativize in English.

Pretesting. Control and experimental group subjects were pretested on their knowledge of English relativization, using a variety of tests that had been used in previous research as well as tests developed specially for the experiment. To be sure that a full range of relativization was assessed, subjects completed both written and oral tasks. The written measure included four sections. Section $A$ was a 48-sentence grammaticality judgment task, with 8 sentences representing each type of relativization. Of the 8 sentences, 4 were correct and 4 contained an error of pronoun retention. ${ }^{6}$ The 48 sentences were presented to subjects in random order so that subjects did not view several of the same sentence type or two sentences together that differed only by the pronoun retention error. Examples of each sentence type judged by native speakers (in correct version) are shown in (2a-f):

(2a) The girl who was sick went home.

(2b) The girl who I saw was pretty.

(SUBJECT)

(2c) The girl who I gave the present to was absent.

(2d) I found the book that John was talking about.

(2e) I know the girl whose father died.

(DIRECT OBJECT)

(INDIRECT OBJECT)

(OBJECT OF A PREPOSITION)

(POSSESSIVE)

(2f) The person who John is taller than is Mary.

(OBJECT OF A COMPARISON)

Section B of the written pretest was a sentence combination task, ${ }^{7}$ as in (3). Subjects were directed to combine the sentences together, beginning with the first sentence and not omitting any of the information contained in either of the two sentences. Subjects were explicitly prohibited from using any coordinating conjoiners such as and, or, because, when, or since. Section $\mathrm{C}$ was similar to the sentence combination task in Section B, but followed a more guided format of sentence completion; in addition to the two sentences to be combined, part of the output sentence was also provided, and subjects were asked to supply the missing words, ${ }^{8}$ as in (4).

(3) The book is very interesting. The book is under the chair.

(4) The man is coming today. The man painted the house last month.

The man last month is coming today.

The final section, Section D, was a grammaticality judgment task similar to Section A but consisting of 29 sentences. ${ }^{9}$ Of the total, 13 sentences were correct and 16 contained errors. This pretest differed from the first in that four possible error types were present-errors of nonadjacency of $\mathrm{HN}$ and RP, errors of pronoun retention, errors of incorrect relative marker morphology, and errors of inappropriate relative marker omission. Examples of sentences with each possible error type are given in (5a-d):

(5a) The woman ran away whose sister came. (nonadjacency)

(5b) I saw the girl who the boy hit her. (pronoun retention) 
$\begin{array}{ll}\text { (5c) I left my coat in an office who was locked. } & \begin{array}{l}\text { (incorrect relative-clause marker } \\ \text { morphology) }\end{array} \\ \text { (5d) The man saw the girl is my brother. } & \text { (inappropriate omission) }\end{array}$

At the start of the written pretest, subjects were informed that there were no errors in spelling, and that spelling should not enter into their decisions. This was to eliminate judgments made solely on the basis of the who/whom distinction. The form whom was deliberately excluded from all instructional and control treatments. Very simple, everyday vocabulary items were employed in the test items. Nevertheless, throughout the administration of the written pretest, subjects were permitted to ask questions about vocabulary.

Additionally, an oral measure of relativization production was individually administered to all subjects as a part of the overall pretest. The oral pretest was audio-recorded and transcribed. The first part of the oral measure consisted of six sets of very similar pictures depicting people involved in some sort of action, one set of four for each relative clause type. ${ }^{10}$ The people in each picture were labeled with numbers, and the general oral elicitation procedure consisted of asking subjects to identify the numbered person beginning with the phrase, "Number 1 is the ..."

Because it had been previously reported that subjects sometimes responded to this elicitation measure with structures other than relative clauses (Hyltenstam, 1984), a set of elicitation techniques that moved subjects from completely unstructured elicitation through guided sentence completion (only if necessary) was developed for this experiment. The first three steps of the elicitation were unguided: Step (1) Initial Elicitation (e.g., "Who is Number 4?"); Step (2) Format Focus (when subjects did not follow task directions, e.g., "l'd like you to answer in a complete sentence. Number 4 is ... "); Step (3) Information Focus (when subjects directed their attention to some irrelevant portion of the drawing, e.g., "Now you're telling me about the cat. Can you also tell me about the person?"). If the unguided elicitation did not result in an attempt to produce a complex sentence, three steps of guided sentence completion, each supplying progressively more elements of the target relative clause, were employed: Step (4) the HN only was modeled; Step (5) the HN and the relative pronoun were modeled (for SUBJECT and POSSESSIVE relative clause types, if no attempt at producing a relative clause was made, the item was abandoned at this point); and Step (6) the HN, the (object-function) RP, and the subject of the relative clause (for DIRECT OBJECT, INDIRECT OBJECT, OBJECT OF A PREPOSITION and OBJECT OF A COMPARISON relative clause types) were modeled. Scores were weighted according to the number of elicitations required in order to reflect total control, partial control, and no control of each type of relativization. No points were deducted, however, for the Format Focus type of elicitation (see Doughty, 1988, for a complete account of the elicitation procedures).

The final portion of the oral elicitation of relative clause knowledge utilized a picture of a park scene that integrated scenes, each describable by only one of the six relative clause types. ${ }^{11}$ The purpose of this measure, the administration of which also followed the above procedures, was to provide an elicitation environment in which subjects would not be focused repeatedly on any one type of relativization for an extended period of time. 
Treatment period. After the extensive pretesting was completed, subjects attended 10 working days of treatment, either experimental or control (these are described in detail in the Materials section). Each day of the treatment period subjects came to a computer laboratory, at their convenience between the hours of noon and 5 P.M., and followed the assignment of completing one "lesson" each day. Each day's lesson was copied onto individual diskettes labeled with subject numbers to ensure that subjects would receive the same kind of treatment throughout the experiment. ${ }^{12}$ On the first day of the treatment period, the researcher presented a brief vocabulary lesson consisting of computer terminology, and provided diagrams and instructions on how to operate the computer and how to call the lessons up to the screen. After one or two days, subjects were able to handle this without assistance from the researcher.

The researcher was present at all treatment sessions to ensure that subjects only viewed the assigned lessons and did not work together or consult dictionaries. Subjects were permitted to ask questions of the researcher, but only those questions pertaining to the operation of the computer or those totally irrelevant to the task at hand were answered. Subjects kept journals of all other questions (e.g., vocabulary and grammar questions) and were invited to attend a review session held after the conclusion of the experiment, during which all the tests and experimental sessions were discussed at length and subjects' questions were answered freely.

Throughout the experimental treatment period, subjects were tested daily on their comprehension of the lesson material. The comprehension tests were built into the overall lesson and added to the lesson-like nature of the experimental treatment. To test their comprehension, subjects answered two questions and were required to write a recall summary of the text that formed the basis of the experimental and control treatments (the two comprehension measures are described in the Materials section). The subjects were directed to write the recall summaries in their native language so that $\mathrm{L} 2$ production constraints would not interfere with the assessment of comprehension.

Posttesting. At the conclusion of the experimental treatment period, all subjects were tested immediately to determine posttreatment knowledge of relativization. The procedures followed during the administration of the posttesting measures were very close to those conditions surrounding the pretest evaluation. Two of the same written test sections (A and B) were used again, and two different, but parallel, sections comprised posttest Sections $C$ and $D$. The primary change in the differing sections was substitution of different, but similarly simple, lexical items. As before, subjects were permitted to ask any questions about vocabulary. The sections of the written and oral posttests were presented in different orders, and within same sections, items were presented in a new random ordering, different from that employed in the pretesting sessions.

In order to provide native speaker baseline data, all pre- and posttest measures were also administered to seven native-speaking English subjects of about the same age and level of education as the non-native-speaking (NNS) subjects who participated in the study. ${ }^{13}$ 


\section{Materials}

In response to the urgent need for detailed reporting of the SL instructional component of effect-of-instruction studies, special care was taken in the design, specification, and experimental presentation of the instructional treatment. The threefold process of considering approach, method, and procedure (instructional techniques, in particular) was adopted in the development of the relativization instruction (Richards \& Rodgers, 1986). To address the first research question regarding the effects of instruction on the acquisition of relativization in ESL, a comprehension-based approach to language teaching was adopted. This approach emphasizes that language acquisition cannot proceed in the absence of comprehension. Specifically, "the learner's exposure to a target language is not in itself a sufficient condition for SLA, but rather what is essential is not merely that target language input be present, but also that the learner comprehend the message therein contained" (Pica, Young, \& Doughty, 1987, p. 737).

As the objective of the comprehension-based approach to language teaching is to promote the acquisition of the $\mathrm{L} 2$ through the facilitation of input comprehension, the instructional goal of the relativization experiment was to encourage the comprehension of material that contained sentences with particular relative clauses. These relative clauses were of the OBJECT OF A PREPOSITION type. As noted earlier, it was assumed that if markedness relationships are relevant in instructed IL development, then relative clauses, as structures that enter into implicational markedness relations, are most effectively taught by exploiting the learners' ability to generalize or to project the instruction from marked to less marked contexts of relativization.

Much of the comprehension-based acquisition research informed the method and instructional techniques incorporated into the design of the relative clause instructional treatment (cf. Day, 1986; Gass \& Madden, 1985). Method of instruction, defined by Richards and Rodgers (1986) as an overall plan for the presentation of language teaching material that is procedural in nature, involved the incorporation of the relative clause instruction into computer-assisted reading lessons using a range of instructional techniques. CALL (computer-assisted language learning), therefore, was not the object of the investigation; rather, the computer format enabled the presentation of the relative clause instruction. There are many reasons for using the computer as a tool in basic research (Doughty, 1987; Pedersen, 1987). In this case, the advantages were those of convenient and controlled administration of the experimental and control treatments and permanent availability of the relativization instruction for future analysis in conjunction with the effect-of-instruction findings that obtained.

Finally, in order to gain insight into the instructional technique that best facilitates the acquisition of relativization, two experimental instructional treatments were employed to serve as the aids to comprehension that have been identified as potentially crucial to SLA. One experimental instructional technique was derived from an interactional view of what makes input comprehensible and was called meaningoriented instruction. The other instructional technique was derived from the structural view of language acquisition that "language is a system of structurally related elements for the coding of meaning" and that the goal of language learning is, 
therefore, the mastery of the rules governing the related elements (Richards \& Rodgers, 1986, p. 17). This technique was known as rule-oriented instruction.

To summarize, the main question of interest was whether instruction would have an effect on the rate of acquisition of English relativization. Groups of subjects who received exposure to marked relative clause data plus an instructional treatment were compared with a control group that was provided only with the marked relative clause laden sentences. While keeping the language teaching approach, method, and lesson design constant, two different experimental instructional techniques were compared to the exposure-only control group in order to determine whether a differential effect for meaning-oriented versus rule-oriented instruction would obtain within an overall comprehension-based approach to the teaching of English relativization. Henceforth, the two experimental groups and one control group will be referred to as MOG (meaning-oriented instructional group), ROG (ruleoriented instructional group), and COG (control group).

The discussion will now turn to a more detailed description of the method and instructional techniques employed in the relativization instruction. To engender face validity of the experimental and control relative clause treatments for subjects, both instructional (MOG and ROG) and control (COG) treatments were contained within the same second language computer-assisted reading lesson format. The pedagogical goals for subjects, which were stated daily, were (a) to read and comprehend a text and (b) to demonstrate comprehension by answering questions and writing a recall summary in their native language. The texts that provided the basis for the daily lessons each consisted of five or six sentences, all containing an OBJECT OF A PREPOSITION type relative clause. A total of three complete stories was created for use in the experiment. The text of each story was divided into several parts, resulting in 10 days of instruction. The topics of the texts, which are typical of those used in ESL materials, were (a) a dilemma over whether to disconnect the life-support system of a loved one, (b) a decision about whether and whom to marry, and (c) the awarding of a population growth permit to one of a number of applicants in the year 2087 .

The format of the lessons was the same for all experimental and control groups. Figure 3 illustrates the overall pedagogical design of the experimental and control treatment sessions. Each computer-assisted reading lesson contained a text that appeared on the screen in three sequential reading-skills formats-a skimming format, an in-depth reading format, and a scanning format-followed by the two measures of comprehension. As can be seen in the figure, the experimental manipulation occurred during the Reading for Understanding portion of the reading lesson. Throughout the computer-assisted reading lesson, any portion of the overall lesson that could be considered a part of the experimental treatment was presented to subjects in a highly controlled manner. However, whenever it was advisable to allow students to control the progress of the lessons, user control was activated by the program. For example, subjects controlled the amount of time they had for understanding the task direction screens at each lesson juncture (e.g., "how to skim," "why and how to read carefully," "how to scan," "answer scanning questions," and "write a recall summary in your native language"). However, any portion of the overall lesson that was a part of the experimental treatment (e.g., all text presenta- 


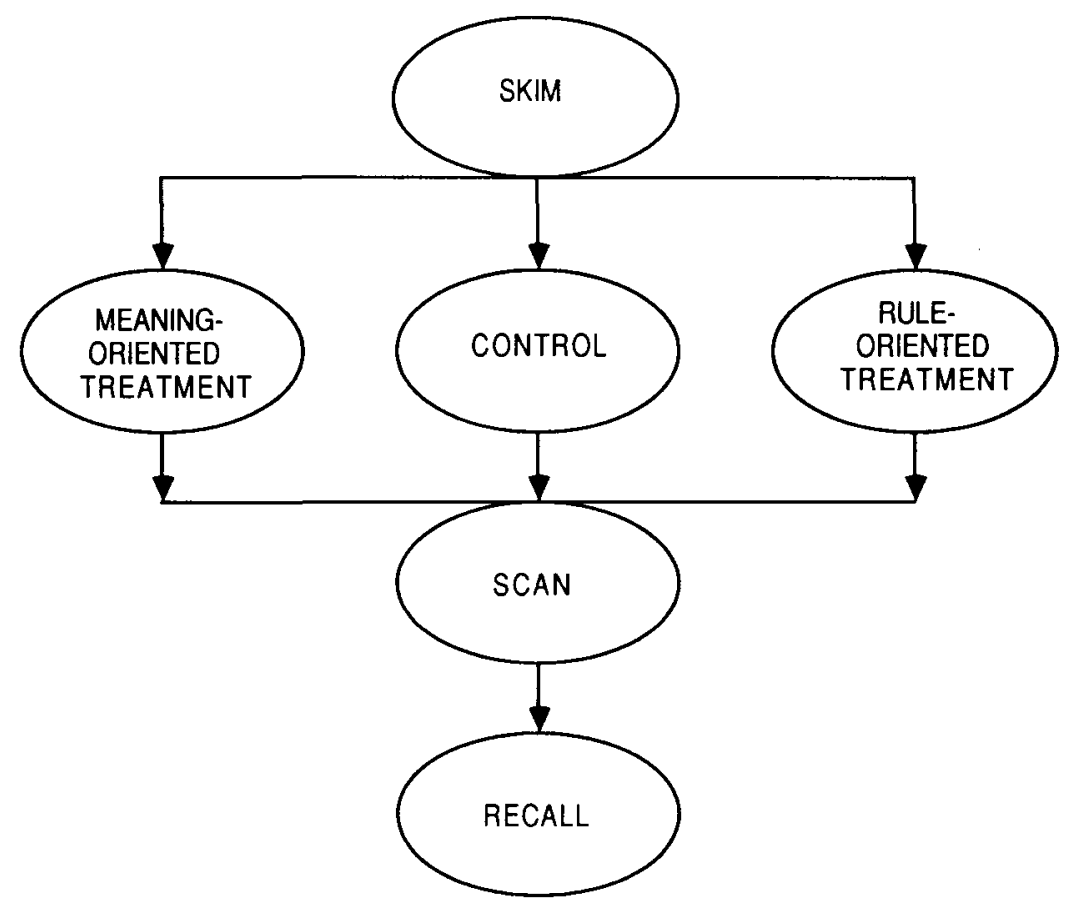

SKIM: $\quad$ Students are instructed to skim for overall content. Computer guidance is provided by highlighting.

READ: $\quad$ Students are instructed to read the entire passage and to attempt to understand most of it. The two experimental groups are given assistance in comprehension. The control group is just given time to read.

SCAN: $\quad$ Students are instructed to study some scanning questions. The passage is then presented again, and the students must answer the questions.

RECALL: $\quad$ Students are instructed to write a summary of the passage in their $L 1$.

Figure 3. Overall experimental and pedagogical design.

tions and relative clause instruction) was under computer timing control and thus was presented to subjects for nearly uniform periods of time.

In the first portion of the reading lesson, all three groups of subjects were instructed to skim only highlighted sentences for the purpose of obtaining a rapid understanding of the main focus of the text. Highlighted material included the title of the story and the first and last sentence of the text. For each group, the skimming session lasted exactly 30 seconds. The second portion of the reading lesson was experimentally manipulated, and, consequently, the format of the material presented on the computer screen during Reading for Understanding was different for each of the three groups. Nevertheless, at the outset of this portion of the lesson, all subjects were instructed to read the material for the purpose of understanding as 
much of the information in the text as possible, were encouraged to use all resources presented to them on the screen to aid in their comprehension, and were notified in advance that they would be expected to answer questions and write a recall summary later on in the session.

During Reading for Understanding, subjects viewed each sentence from the original text consecutively in a narrow window at the top of the screen. For the two experimental groups only, another window containing the experimentally manipulated instructional treatment appeared in a larger window in the remaining lower screen area. The instructional techniques varied for the MOG and ROG experimental groups. Control subjects viewed only the sentences in the narrow top screen (the remaining screen area was blank). The MOG subjects received both lexical or semantic rephrasings and overall sentence-clarification instructional techniques via the lower screen area instructional window.

Lexical information was available through Dictionary Help, in which words from the text sentence were highlighted and listed (either singly or in phrasal combination) together with one or more of the following kinds of information: referent clarification (e.g., referent clarification for a personal pronoun), semantic rephrasing, or an equivalent, but perhaps more common, lexical item. Dictionary Help remained on the screen for exactly 2 minutes and was always presented in conjunction with the relevent text sentence, which was visible in the upper screen window. Explanation consisted of a screen of expansion or clarification of the content of the original sentence using the screen presentation features of highlighting and capitalization to draw subjects' attention to the content and structure of the OBJECT OF A PREPOSITION relative clauses within the matrix sentence (e.g., the relationship of the RP to the $\mathrm{HN}$ ). Explanation also remained on the screen for exactly 2 minutes, always in conjunction with the original sentence.

The ROG subjects viewed a program called Animated Grammar ${ }^{14}$ during Reading for Understanding. Essentially, this program provided instruction on relativization through a combination of explicit rule statement and on-screen sentence manipulation. Subjects were first taken, in animated fashion, through the decomposition of the original text sentence (which was always visible in its entirety in the narrow window at the top of the screen). The complex sentence containing a matrix clause and an OBJECT OF A PREPOSITION relative clause was reduced, step by step, to two simple sentences with coreferential nouns. The steps involved the following: the identification and labeling of the RP in the relative clause and the HN in the matrix clause; information showing where the RP came from and its subsequent replacement by a duplicate of the $\mathrm{HN}$; information about the position of the duplicate noun with respect to the verb phrase (where necessary); the identification of the original main and relative clauses; and, finally, the separation of the two clauses into two simple sentences. At each step both a rule and an animated process were presented to subjects simultaneously. Next, ROG subjects viewed exactly the reverse of the sentence decomposition process-the stepwise recombination of the two simple sentences into the original complex sentence with matrix and OBJECT OF A PREPOSITION relative clauses. The total time for viewing the decomposition and recombination processes was exactly 4 minutes per sentence. 
As noted earlier, COG subjects simply viewed only the original text sentences, one by one, during the Reading for Understanding portion of the computer-assisted reading lessons. As the continued participation of control subjects was crucial to the experiment, each sentence remained on the screen for $2 \frac{1}{2}$ minutes. To have required control subjects to view one sentence for 4 minutes would likely have proved to be highly unmotivating. It is believed that the time spent viewing each original text sentence was similar for all three groups because the experimental groups viewed both the sentence and the lower screen instruction window for a total time of 4 minutes, and the control subjects had $2 \frac{1}{2}$ minutes to study only the original sentence. $^{15}$

After the completion of Reading for Understanding, the computer program moved subjects on to the third portion of the overall reading lesson, Scanning (which was again the same for all three groups, as shown in Figure 3). Subjects were directed to scan through the material for specific kinds of information in order to answer two scanning questions presented both before and after the timed presentation of the original text. Scanning time was limited to exactly 1 minute by the main computer program. Subjects were given as much time as they needed to answer the questions, and then were directed to write the recall summary for the day's material in their native language, also in untimed fashion.

\section{Reformulation of Research Questions}

More precise specification of the effect-of-instruction research questions emerged during the development of the experimental procedures and instructional materials for the study. The general research questions, reformulated in terms of the target of instruction (the subsystem of relativization), the instructional techniques (comprehension approach plus meaning-oriented aids to comprehension versus rule-oriented aids to comprehension), and the sequence of instruction (marked OBJECT OF A PREPOSITION type relative clauses), were:

1. Does SL instruction affect the rate of acquisition of relativization by ESL subjects? If so,

2. Do meaning-oriented instructional techniques and rule-oriented instructional techniques differently affect the acquisition of relativization? and

3. Does SL instruction which utilizes marked relative clauses (OBJECT OF A PREPOSITION-type) facilitate the acquisition of other types of relative clauses?

\section{HYPOTHESES}

Previous research on instructed IL development, in general, and on the acquisition of relativization, in particular, motivated four hypotheses pertaining to the effectiveness of SL instruction. In light of studies that have given at least some indication that instruction can increase the rate of acquisition of a particular structure in IL development, the first hypothesis of the study was:

Hypothesis 1: Instruction has a positive effect on the rate of acquisition of relativization. 
Though it is possible that the lack of conclusive evidence in findings of previous methods comparisons studies may have been due to a repeated failure to operationalize the instruction variable, the second and third hypotheses of the present study were nevertheless formulated in light of the fact that none has ever shown the superiority of one method of instruction over another. The motivation for these hypotheses also reflects the fact that, because the question of precisely how the grammar of a SL is internalized is still undetermined, the interactional view and the structural view of language teaching each forms the bases of several instructional approaches in contemporary SL classrooms.

Hypothesis 2: SL instruction that is semantically and interactionally based (i.e., the meaningoriented instructional techniques) has a greater effect on the ability to relativize than does no instruction; and

Hypothesis 3: SL instruction that is structurally based (i.e., the rule-oriented instructional techniques) has a greater effect on the ability to relativize than does no instruction.

Finally, in accord with theoretical arguments in favor of advantages to acquisition that are evident in the implicational relationships that are inherent in markedness conditions, and in light of previous research that has demonstrated a possible markedness association for relativization, the fourth hypothesis of the study was motivated:

Hypothesis 4: Instruction that targets marked relative clauses (e.g., relative clauses that are low on the NPAH-in this study, OBJECT OF A PREPOSITION type) will generalize to unmarked contexts of relativization.

\section{RESULTS $^{16}$}

\section{Preinstructional Knowledge of Relativization}

Figures 4, 5, and 6 display subjects' pretest knowledge of relativization (i.e., measured by combining written and oral pretests) in the form of implicational scales that are arranged according to the NPAH. A one-way analysis of variance indicated that there was no significant difference among the MOG, ROG, and COG groups in knowledge of relativization at the outset of the experiment, $F=1.28, d f=2 / 17$, n.s. ${ }^{17}$ A random assignment of subjects to one of each of the three groups resulted in the following distribution of L1s: MOG consisted of 3 Japanese speakers, 2 Italian speakers, and 1 speaker each of Turkish, Spanish, and Mandarin Chinese; ROG included 2 Japanese speakers and 1 speaker each of Turkish, French, Mandarin, and Spanish; and COG comprised 5 speakers of Japanese and 1 Russian speaker. Consequently, it was particularly important to demonstrate the homogeneity of relativization ability among all subjects prior to their exposure to experimental and control treatments. 


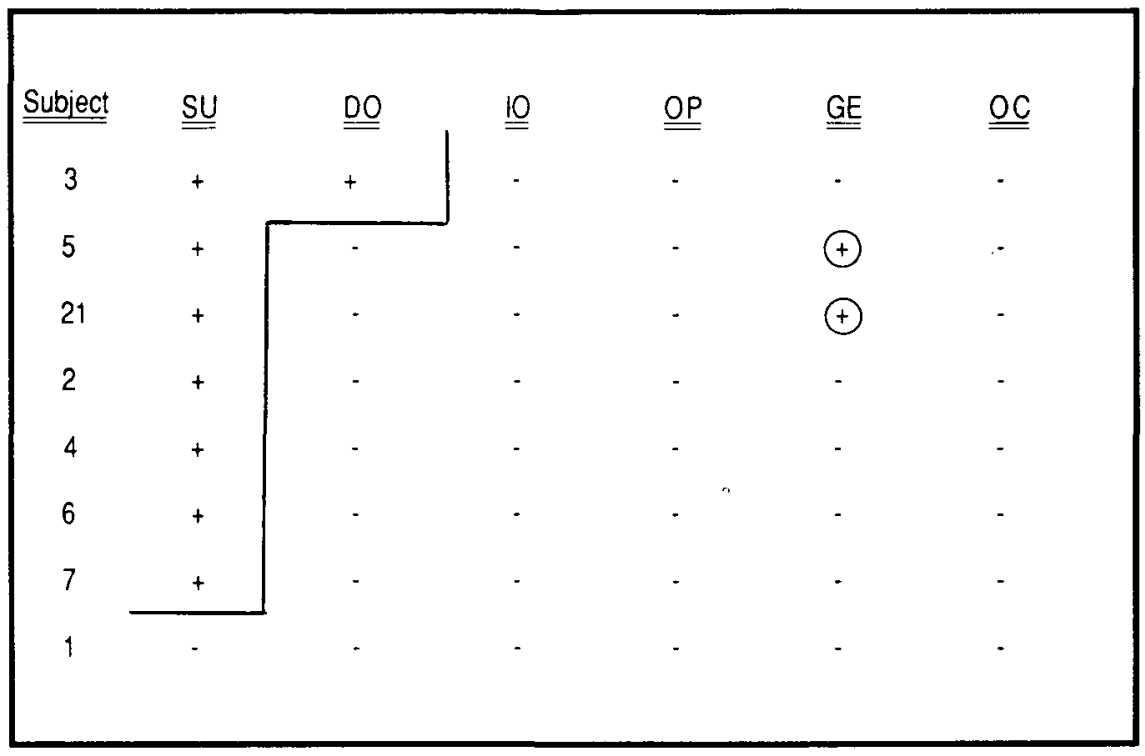

Scaling according to the NPAH. Criterion $=70 \% \quad$ Scalability $=.95$
$\mathrm{SU}=$ Subject
$\mathrm{OP}=$ Object of a Preposition
DO = Direct Object
$\mathrm{GE}=$ Genitive
10 = Indirect Object
$O C=$ Object of a Comparison

Figure 4. Preinstructional knowledge of relativization by MOG subjects.

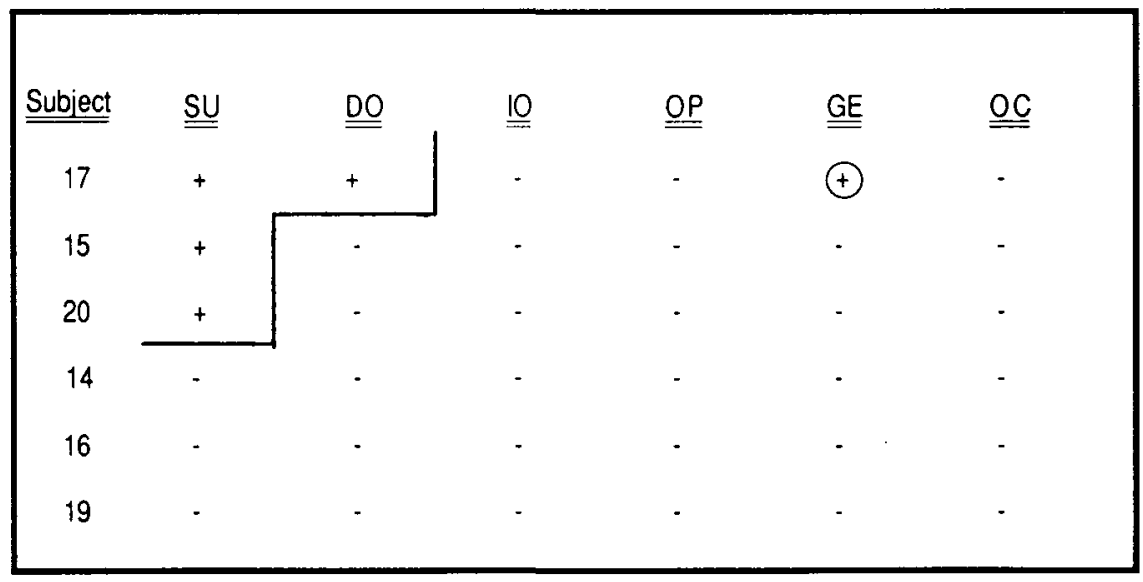

Scaling according to the NPAH. Criterion $=70 \% \quad$ Scalability $=.965$
$\mathrm{SU}=$ Subject
$O P=$ Object of a Preposition
$\mathrm{DO}=$ Direct Object
$\mathrm{GE}=$ Genitive
$10=$ Indirect Object
$O C=$ Object of a Comparison

Figure 5. Preinstructional knowledge of relativization by ROG subjects. 


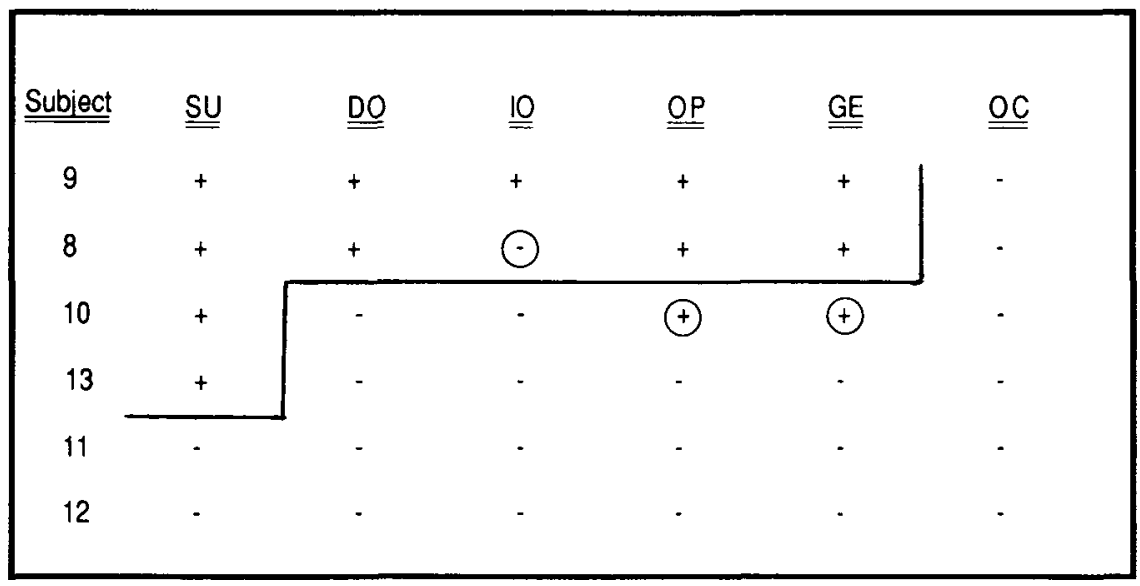

Scaling according to the NPAH. Criterion $=70 \% \quad$ Scalability $=.875$

$\mathrm{SU}=$ Subject

$\mathrm{DO}=$ Direct Object

$10=$ Indirect Object

$\mathrm{OP}=$ Object of a Preposition

$\mathrm{GE}=$ Genitive

$\mathrm{OC}=$ Object of a Comparison

Figure 6. Preinstructional knowledge of relativization by COG subjects.

\section{Effect of Instruction}

The primary research question of this study involved examining the relationship between SL instruction on the subsystem of relativization and subjects' improvement in English relativization ability. Figure 7 displays the total scores (written plus oral) obtained by subjects on the pre- and posttest measures of relativization. Though subjects in the three groups (MOG, ROG, and COG) began the experiment at the same level of relativization ability, the percent change scores for each group suggested that the subjects were, in some way, affected by the treatment and that this effect was particularly large in the cases of the two experimental groups (MOG = $\uparrow 49.30 \%$; ROG $=\uparrow 55.25 \%$; and $\mathrm{COG}=\uparrow 12.00 \%$ ).

Hypothesis 1 predicted that SL instruction would positively affect the rate of acquisition of relativization by ESL subjects. A paired samples $t$ test comparison of pre- and posttest scores indicated that highly significant improvement in relativization ability was evidenced in all three groups: $\operatorname{MOG}(t=7.60, d f=7, p<.0001)$; ROG $(t=4.88, d f=5, p<.005)$; and COG $(t=6.27, d f=5, p<.002)$. Thus, Hypothesis 1 was supported in that both instructed groups (MOG and ROG) improved greatly in English relativization, but it was surprising to discover that control subjects improved in relativization ability as well. 


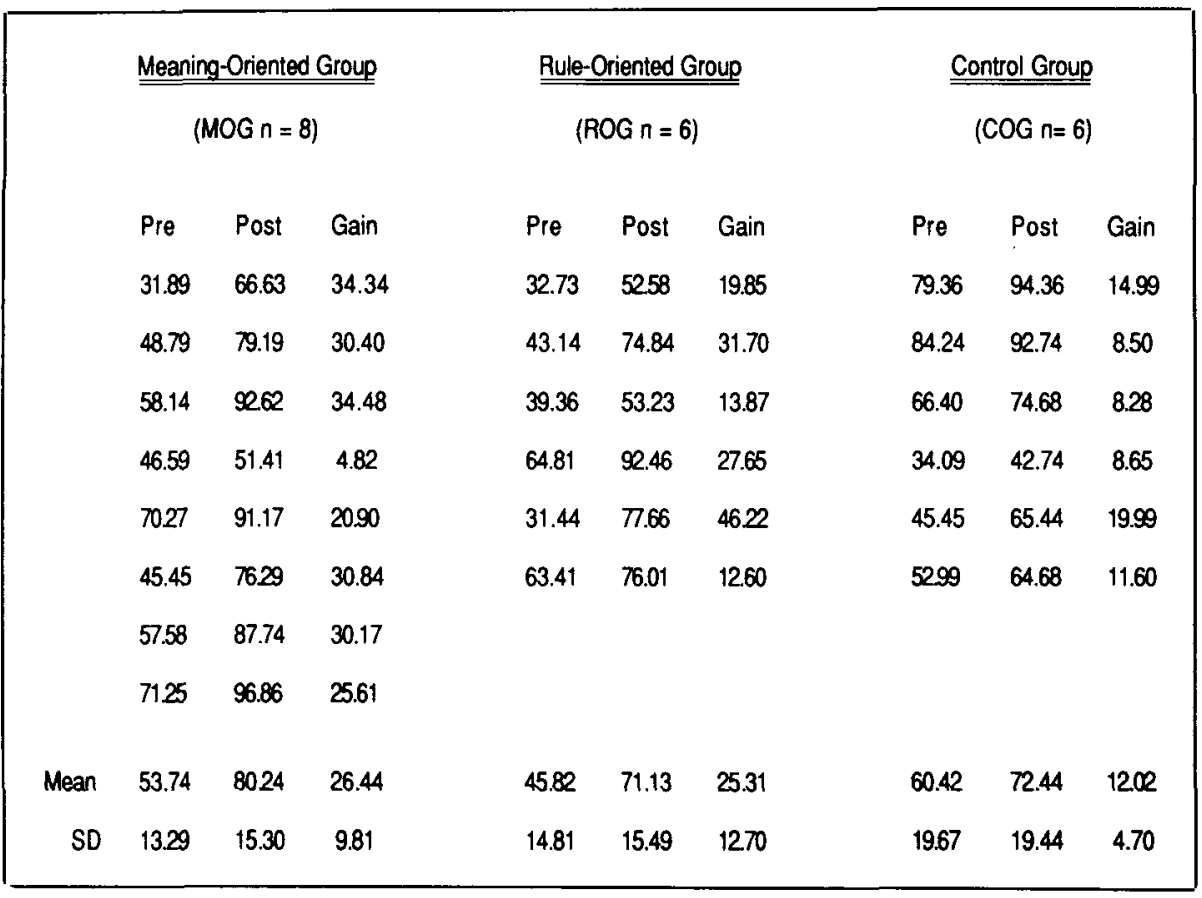

Figure 7. English relativization ability: Pretest, posttest, and gain scores for MOG, ROG, and COG subjects.

\section{Effect of Instructional Procedure}

The secondary research question of this study sought to probe the relationship between experimental (exposure plus instruction) and control treatments (exposure only) to determine if an overall effect for instruction obtained. The testing of the first hypothesis revealed that there indeed was an effect for both instructional treatments, but that this was also the case for the control group. However, the earlier comparisons of the percent change in relativization across the three groups had indicated that the effects for treatment were potentially greater for the two experimental groups than for the control group.

Hypotheses 2 and 3 predicted that in each experimental case (MOG and ROG), the instructional treatment would have a greater effect on relativization ability than would the control (COG) treatment. To compare the amount of improvement in relativization ability across the three groups, gain scores were calculated for each subject by subtracting the pre- from the posttest score (also shown in Figure 7). The mean gain scores of the two experimental groups were similar (MOG: $\bar{X}=26.49$, ROG: $\bar{X}=25.31$ ), and both were more than double the mean gain score that was observed for the control group (COG: $\bar{X}=12.02$ ). Additionally, a one-way analysis 
of variance indicated that there was a significant differential effect for the treatments across the three groups, $F=4.39, d f=2 / 17, p<.029$.

In order to determine where the treatment effects obtained among the three groups, a multiple comparison of groups was performed. The results of the multiple comparisons revealed no difference between the two experimental groups (MOG vs. ROG: $F=0.47, d f=1 / 17$, n.s.) and significant differences between each of the experimental groups and the control group (MOG vs. COG: $F=7.63, d f=1 / 17$, $p<.013$; ROG vs. COG: $F=5.67, d f=1 / 17, p<.029)$. Thus, both Hypotheses 2 and 3 were supported in that both experimental treatment groups whose subjects had received instruction plus exposure to sentences with OBJECT OF A PREPOSITION type relative clauses were shown to have improved significantly more than did the control group, which received exposure only to the marked relative clause sentences.

It should be noted, at this point, that only immediate effects for instruction have been demonstrated. It was not possible to administer a delayed posttest, though this would have been a desirable component of the experiment. By the start of the following semester, when a delayed posttest was considered, many subjects who had participated in the study had left the United States, and those who remained had scattered and encountered a variety of different experiences with the target language. Thus, the controls, which provided a crucial underpinning for the study, were absent at the time of a potential delayed posttest, which could have provided information about long-term instructional effects.

\section{Effect of Targeting Marked SL Data for Instruction}

Finally, the study addressed the question of the role of markedness in SLA. Hypothesis 4 predicted that instruction that targets marked relative clauses (e.g., relative clauses that are low on the NPAH-specifically, of the OBJECT OF A PREPOSITION type in this experiment) would generalize to unmarked contexts of relativization as would be predicted by the projection model. Figure 8 displays the mean gain scores for each group within all relativization categories. A two-way analysis of variance comparing the group mean gain scores on the factors of treatment by relative clause type revealed (a) the previously identified significant effect for instructional treatment, $F=7.75, d f=2, p<.001$; (b) no overall significant effect for relativization type, $F=1.97, d f=5$, n.s.; (c) an apparent trend for more improvement on relativization at and above the OBJECT OF A PREPOSITION type ${ }^{18}$; and (d) no interaction effect for treatment by relative clause type, $F=0.62, d f=10$, n.s. Thus, Hypothesis 4 was supported in that the marked relativization instructed was shown to generalize to other contexts of relativization.

\section{Comprehension of the Texts}

A mean was taken over each subject's daily comprehension scores, ${ }^{19}$ resulting in an overall score for comprehension of all texts read during the experiment. Comparisons of comprehension scores across the three groups revealed an apparent advan- 


\begin{tabular}{|c|c|c|c|c|c|c|}
\hline Group & SUBJECT & $\begin{array}{l}\text { DIRECT } \\
\text { OBJECT } \\
\end{array}$ & $\begin{array}{l}\text { INDIRECT } \\
\text { OBJECT }\end{array}$ & $\begin{array}{l}\text { OBJECT OF A } \\
\text { PREPOSITION } \\
\end{array}$ & POSSESSIVE & $\begin{array}{l}\text { OBJECT OF A } \\
\text { COMPARISON }\end{array}$ \\
\hline MOG & 11.53 & 29.73 & 35.69 & 39.96 & 23.58 & 26.03 \\
\hline ROG & 20.86 & 32.12 & 24.08 & 31.69 & 15.61 & 24.80 \\
\hline COG & 7.67 & 10.80 & 15.55 & 13.24 & 9.65 & 18.82 \\
\hline
\end{tabular}

Figure 8. Group mean gain scores by relativization category for MOG, ROG, and COG subjects.

tage for the MOG with respect to the comprehension of the reading lesson texts. As judged by native speakers, the MOG subjects' group mean comprehension score was 70.01 , whereas the ROG and COG groups scored 43.68 and 40.64 , respectively. A one-way analysis of variance comparing the differences among the group comprehension score means indicated that the difference among groups is significant, $F=$ $9.648, d f=2 / 17, p<.002$.

In order to determine where the differences in comprehension among the three groups obtained, a multiple comparison of group mean comprehension scores was performed. The results of the multiple comparisons revealed no difference between the ROG and COG (ROG vs. COG: $F=0.143, d f=2 / 17$, n.s.) and significant differences between each of these groups and the MOG (MOG vs. ROG: $F=12.228$, $d f=2 / 17, p<.003$, MOG vs. COG: $F=15.217, d f=2 / 17, p<.001)$. That is, the overall comprehension of the reading texts by the MOG subjects was largely and significantly greater than that of either the ROG or the COG subjects. Thus, while both instructed groups (MOG and ROG) performed equally well on the evaluation of the improvement in relativization ability, and both instructed groups outperformed the control subjects, the MOG subjects alone demonstrated an advantage for comprehension of the content of the material presented in the computer-assisted reading lessons.

\section{Postinstructional Knowledge of Relativization}

The posttreatment knowledge of relativization of the three groups is displayed in Figures 9,10 , and 11 in implicational scales, organized according to the NPAH. These figures may be compared with Figures 4 through 6 for a general view (within the framework of the markedness relations inherent in the NPAH) of the nature of change in relativization ability that obtained in the experiment.

\section{DISCUSSION AND IMPLICATIONS}

Three major findings are evident in this study. First, a strong, positive effect of instruction was demonstrated for both experimental groups, each of which had 


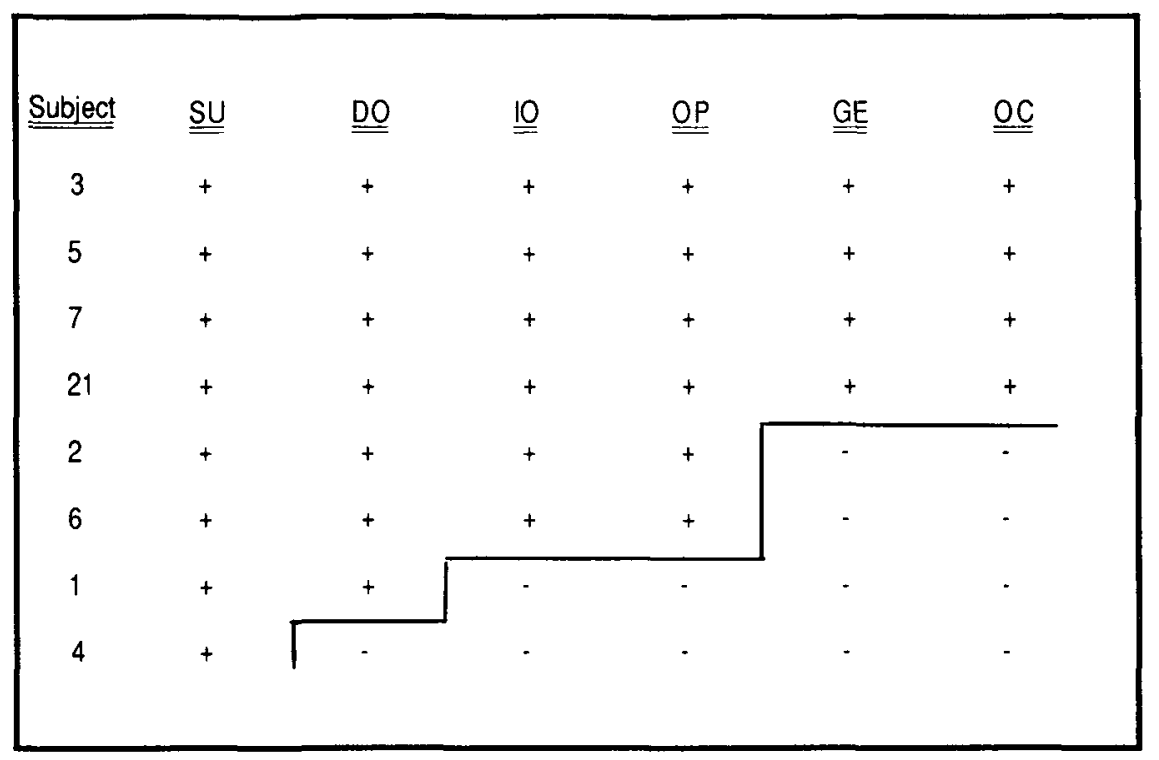

Scaling according to the NPAH. Criterion $=70 \% \quad$ Scalability $=1.00$

$\begin{array}{ll}\mathrm{SU}=\text { Subject } & \mathrm{OP}=\text { Object of a Preposition } \\ \mathrm{DO}=\text { Direct Object } & \mathrm{GE}=\text { Genitive } \\ \mathrm{IO}=\text { Indirect Object } & \mathrm{OC}=\text { Object of a Comparison }\end{array}$

Figure 9. Postinstructional knowledge of relativization by MOG subjects.

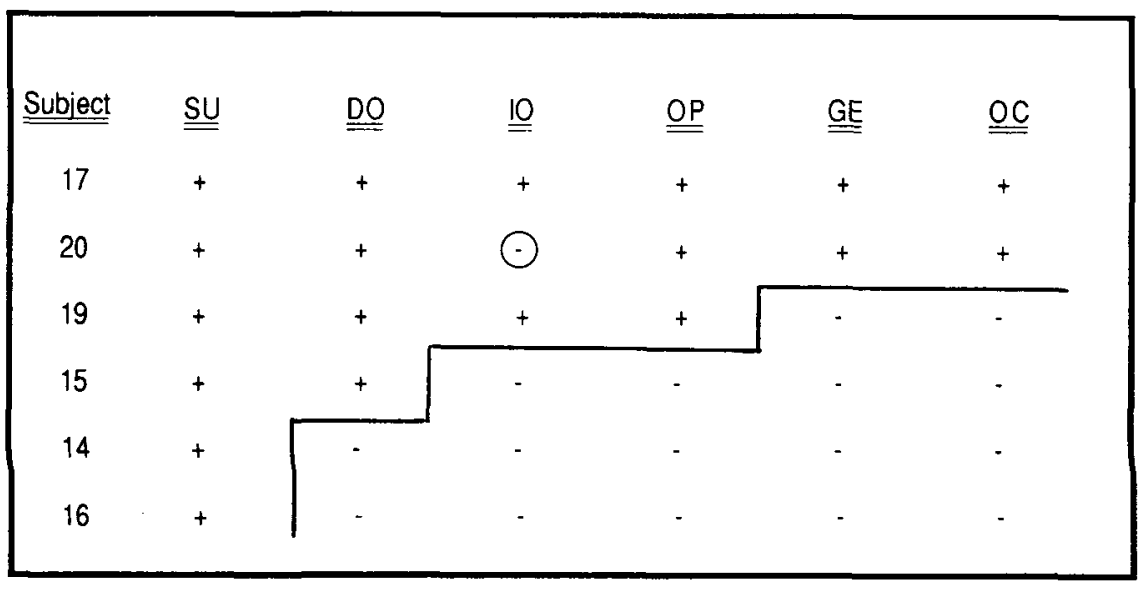

Scaling according to the NPAH. Criterion $=70 \% \quad$ Scalability $=.94$

$\begin{array}{ll}\mathrm{SU}=\text { Subject } & \mathrm{OP}=\text { Object of a Preposition } \\ \mathrm{DO}=\text { Direct Object } & \mathrm{GE}=\text { Genitive } \\ \mathrm{IO}=\text { Indirect Object } & \mathrm{OC}=\text { Object of a Comparison }\end{array}$

Figure 10. Postinstructional knowledge of relativization by ROG subjects. 


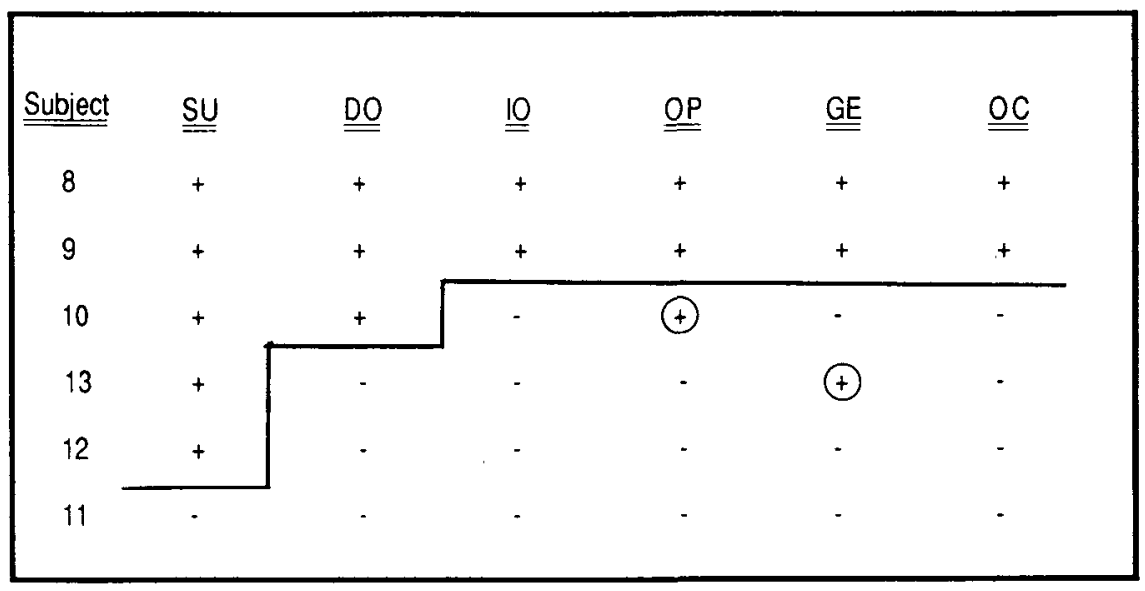

Scaling according to the NPAH. Criterion $=70 \% \quad$ Scalability $=.88$

$\mathrm{SU}=$ Subject

$\mathrm{DO}=$ Direct Object

$10=$ Indirect Object

$\mathrm{OP}=$ Object of a Preposition

$\mathrm{GE}=$ Genitive

$\mathrm{OC}=$ Object of a Comparison

Figure 11. Postinstructional knowledge of relativization by COG subjects.

undergone exposure to marked relative clause data plus relativization instruction. The control group, whose treatment involved only exposure to the marked relative clauses, also experienced some gain in relativization ability; however, this increase was significantly smaller than gains observed for either of the experimental groups.

The second outcome of the experiment was that both instructional techniques employed-meaning-oriented instruction and rule-oriented instruction-were equally effective with respect to gains in relativization. That is to say, both instructed groups made equivalent gains in relativization ability as a result of the experimental treatment. However, while both instructed groups performed equally well on the relativization measure, the MOG alone demonstrated substantial comprehension of the texts that contained the targeted relative clauses. In contrast, the ROG comprehended the material at almost exactly the same, minimal level as did the control subjects.

The third finding of the study was that markedness theory, realized in this instance in the NPAH, pertained to SL development in two ways. Subjects whose preexperimental acquisition of relativization had just begun at the unmarked end of the hierarchy (SUBJECT) benefited from instruction that was focused at a marked position or was relatively low on the NPAH (OBJECT OF A PREPOSITION). In other words, despite receiving instruction pertaining to only one type of relative clause, subjects' relativization ability improved in other contexts of relativization as well. Thus, an unmarked-to-marked ordering was evident in subjects' untutored SL relativization 
development; however, subsequently in the experiment it was possible to provide an efficient shortcut through instruction focused on marked relative clause data. Learners were able to project the rules of the relativization system, as observed in the marked context of use that was emphasized during the instruction, to other contexts of relativization as well.

In order to determine why (a) all three groups in this study improved to some extent in their ability to relativize, (b) the two experimental groups improved significantly more than did the control group, and (c) the two instructed groups performed equally well on tests of relativization despite having received purportedly different forms of instruction, the details of each treatment-MOG, ROG, and COG-were examined in light of the findings. As intended, this type of analysis was possible because all treatment sessions were permanently available for replay in the computer-mediated environment, under precisely the same conditions that prevailed during the experiment. To review, the general approach to the presentation of materials to all groups was comprehension-based-that is, all subjects were directed toward the goal of understanding the reading texts well enough to be able to answer questions and write a recall summary of the content. However, the experimental treatments were explicitly designed to facilitate an improvement in instructed subjects' ability to relativize in English, whereas the control treatment was intended to provide only exposure to English sentences with relative clauses.

Because all groups were exposed to the same set of relativized sentences and because time of exposure was controlled, the greater improvement that obtained for the experimental groups cannot be attributed simply to the availability of additional processing time. Rather, it should be noted that the three treatments varied across groups and differed according to the manner in which the components and facts about relativization were emphasized to subjects. In particular, the two instructional treatments differed greatly from the control treatment with respect to the degree of explicitness with which subjects' attention was drawn to the components of a relative clause and its host matrix sentence. Figure 12 depicts these aspects of the instructional and control treatments along a continuum ranging from explicit focusing of attention on the features of relativization toward more implicit presentation. Clearly, the exposure-only treatment was the most implicit of the three presentation formats.

The equivalent effects of the relativization instruction that obtained in the experimental groups as well as the large differences observed between instructed and exposure-only groups may possibly be explained by examining the nature of the instructional materials presented to each experimental group. Both MOG and ROG instructional treatments were similar in that the major elements of relativization were brought into prominence via perceptual saliency, two levels of redundancy, and the frequency of presentation of marked relative-clause data. Only the marked relative clauses and, to some extent, a degree of redundancy, were available to control subjects. This type of exposure may have been sufficient, however, to account for the small observed gains that they made. The discussion now turns to a detailed accounting of these features within the instructional versus control conditions of the experiment. 


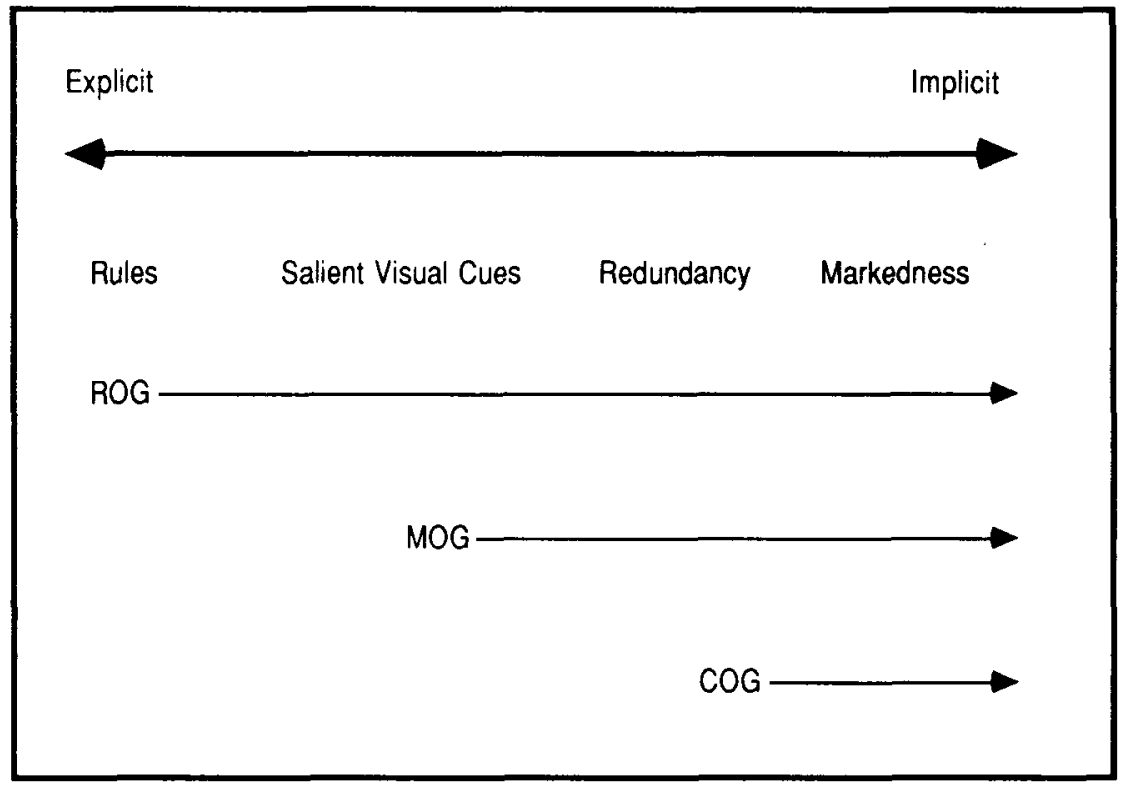

Figure 12. Saliency, redundancy, and markedness in experimental (ROG and $\mathrm{MOG}$ ) and control (COG) treatments.

\section{Saliency}

The ROG subjects' attention was most explicitly drawn to the formal properties of relativization via metalinguistic description, whereas such information was available only implicitly to MOG subjects by the inference of such properties of the HN and RP, which appeared in highlighted and capitalized form. Control subjects were not assisted with any specific features of relativization, and their attention was drawn to relative clauses only to the extent that they were provided with an artificially high proportion of marked relative clauses in the reading texts. MOG and ROG subjects in both instructed groups also experienced the same artificially high and marked exposure to sentences containing relative clauses as did controls; however, the marked data were always presented in conjunction with instructional aids that were aimed at facilitating the acquisition of the targeted marked relative clause structure.

Visual, or nonlinguistic, perceptual cues served to focus ROG and MOG subjects' attention on the major components of relativization. Visual cues are placed toward the explicit end of the continuum in Figure 12 because they served to make the target of instruction particularly salient to the learner. In the case of ROG instruction, visual cues included labeling, disappearance and replacement of elements, and animated movement across the computer screen, all of which were consistently and directly associated with the explicit articulation of relativization rules through synchronized screen presentations. For example, during the sentence combination process, in which one sentence became the relative clause that was then embedded 
into the other sentence, subjects could observe one coreferential noun "turn into" the appropriate RP on the computer screen, see the RP move to the correct position in the clause, and, finally, watch as the relative clause itself moved to the target position adjacent to the HN. Each movement coincided with an explicit statement of the relevant rule.

In the MOG instructional treatment, subjects' visual attention was also captured, this time via computer highlighting as well as typographical capitalization of the juxtaposed HN and RP. However, no reasons underlying the emphasis of the highlighted or capitalized components of the explanatory instruction were offered to subjects, and, for control subjects, no other explicit techniques whatsoever were employed to draw attention to the components of relativization.

Since both instructed groups improved equivalently in relativization, and did so significantly more than controls, perceptual saliency may have been key in the success of the instructional treatment, whereas metalinguistic rule statement apparently was not. Long (1988a) formulated this distinction as one of a contrast between a focus on form versus a focus on forms, where the former refers to instruction that, in some meaningful way, draws learners' attention to TL structure in context and the latter refers only to the presentation of isolated linguistic structures. Based on SLA research to date, Long concluded that "instruction which allows a focus on form produces a faster rate of learning and (probably) higher levels of ultimate SL attainment than instruction with no focus on form" (1988a, p. 15). The discussion will return in the concluding section to the question of a higher level of ultimate attainment for SL learners benefiting from a focus on form.

\section{Redundancy}

The MOG and ROG instructional treatments were further characterized by a much higher degree of redundancy than was the case in the control group treatment. Both the pretesting measure and the redundancy inherent in the instructional treatments were potential sources of repeated exposure to relative clauses within varying sentence formats. As all subjects participated in the pretesting portion of the experiment, it was considered possible that all three groups may have benefited, at least to some extent, from test effect during the treatment and posttesting phases of the study. However, findings of the Eckman et al. (1988) study rule out the test-effect explanation. One group of subjects in this study participated in both pretesting and posttesting sessions but was not exposed to any marked relative clause instruction. These subjects showed no improvement on post- over pretest measures, a finding that is opposite to that which would be expected if a test effect were in operation. Thus, in the present study, the Explanation portion of the MOG treatment and the animated sentence combinations/decompositions of the ROG treatment provided a more likely source of redundancy via reformulations of the original text sentences (the former was aimed at clarifying the story line, and the latter at demonstrating the process of relativization). Redundancy was evident in the control treatment only to the extent that subjects were able to read and reread original text sentences at 
will, at least for the time allowed by the computer program. However, such freedom to reread the text sentences was also a component of the ROG and the MOG instructional treatments.

Though all MOG, ROG, and COG subjects could freely read the relative clausecontaining sentences repeatedly, only the instructed groups were provided with a second level of redundancy. ROG and MOG subjects could apply the instructional reformulations of the original text sentences toward comprehending them, as well as toward internalizing the rules of the English relativization system. Because the instructed groups improved significantly more than did the control group, this additional redundancy level may have been an important feature leading to the success of the instruction.

\section{Markedness}

All sentences that comprised the reading texts were specially formulated to contain marked, OBJECT OF A PREPOSITION type relativization. Furthermore, every sentence in the text to be read during the computer lesson contained such a marked relative clause. The explanation for the finding indicating a certain amount of improvement in all groups could be attributed to the marked nature of the sentences in the reading passages and to the frequent exposure of subjects to such preselected data. The explanation that all subjects could have benefited from exposure to marked data and may have been able to project a degree of understanding of these marked sentences to other domains of relativization fits well with the finding that even the control subjects demonstrated some gain in relativization ability. This argument is particularly convincing in light of the Eckman et al. (1988) study, which discounts the test-effect explanation for the observed control subjects' improvement.

\section{Comprehension and Rule Internalization}

Because the instructed groups made the greatest gains in relativization, perceptual saliency, together with two levels of redundancy and the marked nature of the SL data, appear to have facilitated the internalization of the rules of the English relativization system (see Figure 12). These findings are supported by observations in the SLA literature that noticing the features of the TL is essential to acquisition (Schmidt \& Frota, 1986). That both instructed groups in the present study made equivalent gains in relativization may be explained by the observation that there are a variety of ways of encouraging learners to notice forms other than traditional methods of metalinguistic discussion (Rutherford \& Sharwood Smith, 1988). Such techniques fall into positions from the center toward the implicit end of the continuum shown in Figure 12. While the instruction provided to the MOG group contained none of the explicit rule articulation available to ROG subjects, the MOG subjects' attention was deliberately drawn to those components of relativized sentences that form the connection between the relative and matrix clauses, namely, the RP and the $\mathrm{HN}$, respectively. In terms of the observed gains in relativization ability, a focus 
on meaning and a focus on rules were equally successful techniques, provided that subjects were directed to notice the elements of relativization in the input. Thus, whereas both instructed groups viewed the major elements of relativization as they were brought into prominence through perceptual saliency, and the control group did not, and since both instructed groups outperformed the control group, it is apparent that visual direction of the learners' attention to the elements of the relative clause construction influenced their learning of the relativization system. However, because MOG subjects benefited from the instruction to a degree equal to the ROG group's improvement, it is evident that neither the explicit metalinguistic discussion nor rule elaboration was necessary to facilitate improvement in relativization.

Another primary difference among groups in this experiment was that the MOG group received lexical and semantic assistance, whereas the ROG and COG groups did not. Vocabulary clarification and confirmation was available to MOG subjects together with every sentence during the Reading for Understanding portion of the computer reading lesson. Further elaboration of the content of the texts was also provided to MOG subjects via the Explanation aid to comprehension, which followed the above Dictionary type assistance. Because comprehensible input alone may not be a sufficient condition for SLA, and since attending only to comprehensible input does not ensure grammatical accuracy in the TL, comprehensibility of the input was always fostered in the MOG group in combination with the bringing to prominence of the structural elements of relativization. Consequently, sentences could be understood while simultaneously serving to allow subjects to notice the targeted structure. That MOG subjects did indeed comprehend the texts was revealed in their overwhelming advantage on the reading recall measures.

The finding of significantly greater comprehension on the part of the MOG subjects may be explained by examining the nature of the redundancy levels available in the instructional as well as control treatments. Previous work has pointed to the importance to comprehension of redundancy in the form of exact and semantic repetitions (Pica, Doughty, \& Young, 1986; Pica, Young, \& Doughty, 1987). In the present study, only the MOG instructional treatment incorporated lexical and semantic rephrasings. Where all three groups could have read the exact sentences repeatedly, only the MOG group was provided with instruction involving isolated semantic repetition via the dictionary assistance. Additionally, only the MOG group viewed integrated semantic rephrasing via the reformulations of the original sentences in the explanation portion of the instruction. Thus, the findings of the present study support and reinforce earlier evidence that redundancy is important to comprehension. Specifically, the present findings suggest that semantic repetition may be a redundancy format that is key to subjects' understanding of the input.

The results of this study also support the claims that there are various levels of comprehension involving either or both the semantic and structural components of the input available to be comprehended and that these levels of comprehension do not necessarily depend on, nor interfere with, one another (Gass, 1988). Because the ROG subjects were able to internalize the structural component of the instruction, comprehension of the message was shown not to be a prerequisite of the internaliza- 
tion of grammatical rules. Moreover, since MOG subjects both comprehended the message and internalized the relevant features of the target structure, a focus on meaning was shown not to interfere with the structural level of comprehension.

\section{SUMMARY}

SL instruction was shown to have a positive effect on the rate of acquisition of relativization in English. The two experimental groups, which participated in exposure to relative clauses plus meaning-oriented or rule-oriented instructional treatments, respectively, improved significantly more on the posttest over the pretest evaluation of relativization that did the control group, which participated in the exposure-only control treatment.

The importance of drawing learners' attention to the target of instruction was demonstrated. Both instructed groups improved significantly more than the control group. This advantage was attributed to the instructional techniques that brought the features of relativization into prominence. It was concluded that a range of techniques that focused the attention of subjects on the components of relativization were effective because each of these techniques contributed to the perceptual saliency and redundancy of the targeted structures.

That learners can acquire grammatical structure while minimally comprehending the semantic content of the input containing the structure was demonstrated (see the low performance of ROG subjects on the comprehension measure). More important, it was shown that an emphasis on the overall meaning of the propositional content of the instructional material was not detrimental to the internalization of the features of English relativization and did lead to greater comprehension. In other words, though both instructional treatments were equally successful in facilitating the acquisition of relativization and both were more successful than the control treatment, the meaning-oriented treatment was shown to better facilitate comprehension than was the case in either the rule-oriented or control conditions. This was attributed to the apparently successful combination of a focus on meaning and the bringing to prominence of the linguistic properties of relativization in the MOG treatment (what Long, 1988a, calls focus on form).

The theory of markedness was shown to influence second language development with respect to relativization in two ways: (a) the preinstructional interlanguage relativization ability of subjects was revealed to have begun in untutored, unmarked fashion, and (b) instruction taking into account the markedness relations that comprise the NPAH was shown to provide a shortcut to acquisition by facilitating subjects' improvement across all relativization contexts while focusing on only one marked context of relativization.

\section{CONCLUSION}

The findings of the present investigation, as well as those of several other studies previously discussed (Eckman et al., 1988; Gass, 1982; Pavesi, 1986; Zobl, 1983), 
motivate three important questions for future research. First, none of the studies has addressed the question of long-term effects of instruction that focuses on form. Following is a hypothesis that emerges from (a) the present investigation, where a focus on form (highlighted TL structure in context) proved to be a successful instructional technique, in combination with (b) earlier findings that instruction that focuses only on forms (e.g., isolated linguistic structures) is ineffectual (Long, 1988a). Differences between MOG type and ROG type instructed learners may eventually be manifested in a permanent effect for instruction for MOG type instruction versus a temporary effect for the isolating ROG type instruction. This hypothesis remains untested, however, owing to the difficulty of providing suitable experimental controls over long periods of time in an SL context. The inherently more controlled nature of the FL setting would be an obvious context for future investigation.

Second, findings of studies of markedness and SLA have not revealed how marked data influence instructed IL development. Taken together, the findings of the relativization studies have shown the following: (a) uninstructed subjects follow a developmental pattern that matches the NPAH; (b) generally (i.e., not relativization-focused) instructed subjects appear to progress further down the NPAH and to attain higher criterion levels at each position along the way (Pavesi, 1986); (c) relativization instruction focused on only the SUBJECT position (i.e., the least marked position) enables learners to improve in only SUBJECT type relativization (Eckman et al., 1988; Gass, 1982), whereas instruction at the OBJECT OF A PREPOSITION position (one of the more marked positions) generalizes to enable improvement in other contexts of relativization (Gass, 1982; and findings of the study reported here), and (d) this improvement may be characterized as rapid, and, apparently, if the findings of all the relativization studies are considered, facilitative of a higher level of ultimate SL attainment (though the present study has not shown the latter, and more research is clearly needed).

Findings of the present study, as well as the others cited, all of which indicate that, after receiving instruction incorporating marked linguistic data, "a learner can actually have 'learned' more than he/she has been taught" (Eckman et al., 1988, p. 2), beg the question of how this apparent advantage for SLA occurs. In light of the general interpretation that marked data are maximally generalized from marked to unmarked contexts for acquisition (Eckman et al., 1988; Zobl, 1983), it is troublesome that the findings of at least two studies (the present one and Gass, 1982) indicate that, whereas unmarked data are not generalized beyond their own context, marked data may be generalized in both the unmarked and the marked directions on the $\mathrm{NPAH}^{20}$ The other studies have not addressed this question, as Zobl (1983) looked at a structure with only two contexts-one marked and the other unmarked, ${ }^{21}$ and Eckman et al. (1988) measured improvement in only three of the six possible contexts for relativization. At this point in the research, only one conclusion is clear-cut. Instruction incorporating unmarked data generalizes only to unmarked contexts, whereas instruction incorporating marked data potentially generalizes not only to that marked context but to other contexts as well. How and why this happens are important topics for future research. 
Finally, the issue of an apparent contradiction to the learnability account of the importance of fixed developmental sequences in SLA, which the findings of all the relativization studies emanating from the NPAH markedness framework seemingly constitute, needs to be addressed. The premise of the learnability account is that psycholinguistic processing constraints preclude the learning of any interlanguage structure before the particular processing ability inherent in that structure is acquired (see the research on German word order, e.g., Meisel, Clahsen, \& Pienemann, 1981). Findings on instruction that takes advantage of markedness relationships suggest that focusing on marked structures facilitates the acquisition of different but implicationally related structures. Thus, it is necessary to ask: What is the relationship between psycholinguistic processing and markedness in this instance?

It should be recalled that in accordance with the learnability hypothesis, the subject selection procedure followed in this experiment expressly targeted subjects who were considered ready to acquire relativization but had not yet done so. Readiness of subjects was equated to level of study in an intensive English program by testing the relativization ability of all the program students. In so doing, it was determined that those students attending up to the 300 level had not yet acquired relativization and that those in 600 - and 700 -level classes had acquired relativization, thus revealing 400 - and possibly 500 -level students as those potentially ready to acquire it. During the semester of the actual study (the one following the determination of the level at which students could be expected to be ready to acquire relativization), 400- and 500-level students participated in the study. In fact, of those students who actually participated in the study, 14 out of 20 had already reached criterion in SUBJECT type relativization ability, as measured on the preinstructional test of relativization ability. Subjects who participated in the experimental groups of the investigation demonstrated the benefits of instruction by acquiring the ability to relativize across a variety of contexts for relativization. With respect to the psycholinguistic operations involved, it is apparent from previous studies and from this one that there is a much greater difference between relativization and nonrelativization than there is among the different types of relativization. In other words, the comparison between the process involved in embedding one clause into another to that of producing/comprehending two simple, contiguous sentences reveals a number of psycholinguistic processing differences, whereas all the various types of relativization essentially require the same embedding operations: replace the coreferential NP with a RP; preserve case; move the RP to the beginning of relative clause, if necessary; and move the relative clause to the position immediately following the full-form coreferential NP, if necessary.

The findings of this study and others taken together suggest that once learners reach the point of readiness, other factors, such as markedness, may also influence SLA. Thus, the nature of markedness, and its implications for SLA in general, and instructed interlanguage in particular, must be investigated further, especially if markedness theory has a potential contribution to make to a principled account of learnability. 


\section{NOTES}

1. The term "instructed interlanguage development" was developed by Long (1988b).

2. The discussion of the relativization research presented here is necessarily brief. For a full consideration of the three predictor hypotheses and of the evidence for and against each, see Doughty (1988).

3. The Eckman, Bell, and Nelson (1988) study actually did not figure in the development of the present study's experimental design or control and experimental treatments, as that study was reported after the completion of the present investigation. Fortuitously, however, the Eckman et al. study appeared at such a time as to provide an answer to a question that arose from the present investigation; namely, whether performance of control subjects could be attributed to an effect of the pretest or to the marked nature of the relative clauses present in all treatments of the investigation (see the Discussion section).

4. OBJECT OF A COMPARISON relative clauses (i.e., the least accessible) were not selected because there is no general agreement as to whether such relative clauses (such as "You are the only person who I am taller than") are grammatical in English. Possessive relative clauses (next lowest on the NPAH) were not selected because the English genitive relative pronoun, whose, is radically different from the relative pronouns in all other types of English relativization (see Gass, 1981, for discussion).

5. There was one exception to the overall lack of contact with native English speakers. One of the control subjects reported having a part-time job in one of the university's cafeterias.

6. This was the same test that had been used to assess relativization ability in the general population that served as the pool for subjects. Of course, this was a new administration of the measure, given this time to the actual subjects of the present study as a part of the pretesting battery.

7. Some of the items in this section had been developed by Gass (1982), and others were added for the purposes of this experiment.

8. These sentences were taken from Ioup (1983).

9. Adapted from Gass (1982).

10. Adapted from the measure reported on in Hyltenstam (1984) and kindly supplied in its entirety to this researcher. The adaption involved using half the total pictures possible in the original test, which contained eight pictures for each relative clause type. See Hyltenstam (1984, p. 56) for an example of this elicitation measure (aimed at obtaining SUBJECT type relativization).

11. Adapted from Dunbar and Heike $(1985$, p. 12).

12. For the most part, subjects followed the schedule of one lesson per day. On occasion, however, they could not come to the laboratory during the appointed hours. When this happened, subjects were permitted to do two lessons on the subsequent day.

13. The NS baseline data was utilized in coding and scoring the NNS responses.

14. This program was developed at the Ohio University by M. Soermarmo (1987), who kindly provided the source code to the researcher. The program was changed for the purposes of this investigation in the following ways: the program was rewritten in $\mathrm{C}$ so that it could be incorporated into the main program, and the relativization rule explanations were edited and simplified considerably.

15. One SSLA reviewer hoped that I would address some issues relevant to comparisons of instructional and control treatments. In essence, the reviewer wondered whether, in actual practice, the control treatment may not have been as motivating and also whether simply reading sentences, without any aids to comprehension, truly reflected a naturalistic context. I am able to report that control subjects appeared to be as motivated as experimental subjects by virtue of the fact that they made (as did all subjects) highly favorable comments about the "lessons," and that they returned each day, even though they were not really required to do so. Second, I do feel that reading without any aids to comprehension is quite reflective of some phases of the overall naturalistic reading process. In conjunction with sentence-by-sentence reading, control subjects benefited equally from opportunities to skim, read repeatedly, and scan for meaning. It was only in the treatment portion of the overall lesson that instructed subjects were given advantages (i.e., the very advantages under investigation). I agree with the reviewer's overall comment that even the small gain of the control group was noteworthy, given the conditions under which it was required to participate in order that the experiment be suitably controlled (see Results section for further discussion).

16. Data transcription, coding, and scoring procedures are described in detail in Doughty (1988). Briefly, all oral data were transcribed with the aid of an Apollo DN300 minicomputer and a Sanyo Memoscriber. Written data were keyboarded into computer files by the researcher. The data entry procedures involved coding subject responses according to item score, relativization category, question number, and subject identification number, a process that later facilitated machine analysis of coded data, using the AWK pattern matching program (Aho, Kernighan, \& Weinberger, 1988). All test items, whether written or oral, were equally weighted at 1 point each. The pre- and posttest scores were calculated on the basis of the sum total of written and oral test items. 
17. A second one-way ANOVA indicated that subjects in all three groups scored comparably on the TOEFL exam which they took near the time of the experiment. Thus, if TOEFL can be considered as an overall measure of proficiency, then there was no difference among subjects in general level of second language development at the time of the relativization experiment, $F=.049, d f=2 / 17$, n.s..

18. The statistical procedures applied were not quite sensitive enough to discern the existence of the apparent trend.

19. The comprehension scoring procedure was as follows. The recall summaries, written in subjects' L1s, were evaluated by native speakers or near native-speaking teachers of each language. The evaluators also had a command of English. The evaluators filled out a score sheet that listed the major proposition of each text by marking their judgments in one of three columns: understood completely, partially understood, or not understood at all. The researcher totaled the weighted recall summary scores and combined these with the scanning question scores to arrive at an overall score for comprehension.

20. Michael Long (personal communication, 1990) emphasizes this point.

21. Specifically, personal pronouns.

\section{REFERENCES}

Aho, A., Kernighan, B., \& Weinberger, P. (1988). The AWK programming language. New York: AddisonWesley.

Bailey, K., Madden, C., \& Krashen, S. (1974). Is there a natural sequence in adult second language learning? Language Learning, 28, 235-243.

Bowerman, M. (1979). The acquisition of complex structures. In P. Fletcher \& M. Garman (Eds.), Language acquisition: Studies in first language development (pp. 285-306). Cambridge: Cambridge University Press.

Cook, V. (1973). The comparison of language development in native children and foreign adults. International Journal of Applied Linguistics, 11, 13-28.

Day, R. (1986). Talking to learn: Conversation in second language acquisition. Rowley, MA: Newbury House.

Doughty, C. (1987). Relating second language acquisition theory to CALL. In W. F. Smith (Ed.), Modern media in foreign language education: Theory and implementation (pp. 133-168). Lincolnwood, IL: National Textbook Company.

Doughty, C. (1988). The effects of instruction on the acquisition of relativization in English as a second language. Unpublished doctoral dissertation, University of Pennsylvania, Philadelphia.

Dulay, H., \& Burt, M. (1973). Should we teach children syntax? Language Learning, 24, 245-258.

Dulay, H., \& Burt, M. (1974). Natural sequences in child second language acquisition. Language Learning, 25, $37-53$.

Dunbar P., \& Heike, A. (1985). Building fluency in English. New York: Prentice-Hall.

Eckman, F., Bell, L., \& Nelson, D. (1988). On the generalization of relative clause instruction in the acquisition of English as a second language. Applied Linguistics, 9, 1-11.

Felix, S. (1981). The effect of formal instruction on second language acquisition. Language Learning, 31, 87112.

Gass, S. (1979). Language transfer and universal grammatical relations. Language Learning, 29, 327-344.

Gass, S. (1981, March). From theory to practice. Paper presented at the 15 th annual TESOL convention, Detroit, $\mathrm{Ml}$.

Gass, S. (1982). From theory to practice. In M. Hines \& W. Rutherford (Eds.), On TESOL '8I (pp. 129-139). Washington, DC: TESOL.

Gass, S. (1988). Integrating research areas: A framework for second language studies. Applied Linguistics, 9 , 198-217.

Gass, S., \& Ard, J. (1980). L2 data: Their relevance for language universals. TESOL Quarterly, 14, 443-452.

Gass, S., \& Madden, C. (1985). Input in second language acquisition. Rowley, MA: Newbury House.

Hatch, E. (1983). Psycholinguistics. Rowley, MA: Newbury House.

Hyltenstam, K. (1984). The use of typological markedness conditions as predictors in second language acquisition: The case of pronomial copies in relative clauses. In R. Andersen (Ed.), Second languages: $A$ crosslinguistic perspective (pp. 39-60). Rowley, MA: Newbury House.

loup, G. (1983). Acquiring complex sentences in English. In K. Bailey, M. Long, \& S. Peck (Eds.), Second language acquisition studies (pp. 25-40). Rowley, MA: Newbury House.

loup, G., \& Kruse, A. (1977). Interference vs. structural complexity in second language acquisition: Language universals as a basis for natural sequencing. In $\mathrm{H}$. Brown, C. Yorio, \& R. Crymes (Eds.), On TESOL 77- 
Teaching and learning English as a second language: Trends in research and practice (pp. 159-171). Washington, DC: TESOL.

Keenan, E., \& Comrie, B. (1977). Noun phrase accessibility and universal grammar. Linguistic Inquiry, 8, 6399.

Keenan, E., \& Comrie, B. (1979). Data on the noun phrase accessibility hierarchy. Language, 55, 333-351.

Kennedy, G. (1973). Conditions for language learning. In J. Oller \& J. Richards (Eds.), Focus on the learner (pp. 66-80). Rowley, MA: Newbury House.

Krashen, S. (1977). Some issues relating to the monitor model. In H. Brown, C. Yorio, \& R. Crymes (Eds.), On TESOL '77-Teaching and learning English as a second language: Trends in research and practice (pp. 145-158). Washington, DC: TESOL

Krashen, S. (1982). Principles and practices in second language acquisition. New York: Pergamon.

Krashen, S., Scarcella, R., \& Long, M. (1982). Child-adult differences in SLA. Rowley, MA: Newbury House.

Kuno, S. (1974). The position of relative clauses and conjunctions. Linguistic Inquiry, 5, 117-136.

Lightbown, P. (1981, July). Acquiring English L2 in Quebec classrooms. Paper presented at the conference on Interdisciplinary Perspectives on Language Acquisition Research, Passau, Germany.

Lightbown, P. (1983). Acquiring English L2 in Quebec classrooms. In H. Wode \& S. Felix (Eds.), Language development at the crossroads (pp. 101-120). Tübingen: Narr.

Long, M. (1983). Does second language instruction make a difference? TESOL Quarterly, 17, 359-382.

Long, M. (1988a, June). Focus on form: A design feature in language teaching methodology. Paper prepared for the National Foreign Language Center/European Cultural Foundation Conference on Empirical Research on Second Language Learning in Institutional Settings, Bellagio, Italy.

Long, M. (1988b). Instructed interlanguage development. In L. Beebe (Ed.), Issues in second language acquisition: Multiple perspectives (pp. 115-142). Rowley, MA: Newbury House.

Meisel, J., Clahsen, H., \& Pienemann, M. (1981). On determining developmental stages of second language acquisition. Studies in Second Language Acquisition, 3, 109-135.

Pavesi, M. (1986). Markedness, discoursal modes, and relative clause formation in a formal and in an informal context. Studies in Second Language Acquisition, 8, 38-55.

Pedersen, K. (1987). Research on CALL. In W. F. Smith (Ed.), Modern media in foreign language education: Theory and implementation (pp. 99-131). Lincolnwood, IL: National Textbook Company.

Perkins, K., \& Larsen-Freeman, D. (1978). The effect of formal language instruction on the order of morpheme acquisition. Language Learning, 25, 237-244.

Pica, T. (1983). Adult acquisition of English as a second language in different language contexts. Language Learning, 33, 465-497.

Pica, T., Doughty, C., \& Young, R. (1986). Making input comprehensible: Do interactional modifications help? I.T.L. Review of Applied Linguistics, 72, 1-25.

Pica, R., Young, R., \& Doughty, C. (1987). The impact of interaction on comprehension. TESOL Quarterly, $21,737-758$.

Pienemann, M. (1985). Learnability and syllabus construction. In K. Hyltenstam \& M. Pienemann (Eds.), Modelling and assessing second language acquisition (pp. 23-76). Clevedon, UK: Multilingual Matters.

Prideaux, G., \& Baker, W. (1986). Strategies and structures: The processing of relative clauses (Current Issues in Linguistic Theory 46). Philadelphia: John Benjamins.

Richards, J., \& Rodgers, T. (1986). Approaches and methods in language teaching. Cambridge: Cambridge University Press.

Romaine, S. (1984). Relative clauses in child language, pidgins and creoles. Australian Journal of Linguistics, $4,257-281$.

Rutherford, W., \& Sharwood Smith, M. (1988). Grammar and second language teaching. Rowley, MA: Newbury House.

Sajavaara, K. (1981). The nature of first language transfer: English as L2 in a foreign language setting. Paper presented at the first European-North American Workshop on Second Language Acquisition Research, Lake Arrowhead, CA.

Schmidt R., \& Frota, S. (1986). Developing basic conversational ability in a second language: A case study of an adult learner of Portuguese. In R. Day (Ed.), Talking to learn: Conversation in a second language (pp. 237-326). Rowley, MA: Newbury House.

Schumann, J. (1980). The acquisition of English relative clause by second language learners. In R. Scarcella \& S. Krashen (Eds.), Research in second language acquisition: Selected papers from the Los Angeles Second Language Research Forum (pp. 118-131). Rowley, MA: Newbury House.

Sheldon, A. (1974). The role of parallel function in the acquisition of relative clauses in English. In C. Ferguson \& D. Slobin (Eds.), Studies of child language development (pp. 272-281). New York: Holt, Rhinehart \& Winston.

Soermarmo, M. (1987). Animated grammar [Unpublished software]. Ohio University, Athens. 
Stauble, A. (1978). A frequency study of restrictive relative clause types and relative pronoun use in English. Unpublished manuscript, University of California at Los Angeles.

Wode, H. (1981). Language-acquisitional universals: A unified view of language acquisition. In $H$. Winitz (Ed.), Native language and foreign language acquisition: Annals of the New York Academy of Sciences, 379, 218-234.

Zobl, H. (1983). Markedness and the projection problem. Language Learning, 33, 292-313.

Zobl, H. (1985). Grammars in search of input and intake. In S. Gass \& C. Madden (Eds.), Input in second language acquisition (pp. 329-344). Rowley, MA: Newbury House. 